\title{
Geomorphology of a modern carbonate slope system and associated sedimentary processes: Example of the giant Great Abaco Canyon, Bahamas
}

\author{
Recouvreur Audrey ${ }^{1,{ }^{*}}$, Fabregas Natacha ${ }^{2}$, Mulder Thierry ${ }^{1}$, Hanquiez Vincent ${ }^{1}$, \\ Fauquembergue Kelly ${ }^{1}$, Tournadour Elsa ${ }^{3,4}$, Gillet Hervé ${ }^{1}$, Borgomano Jean ${ }^{5}$, Poli Emmanuelle, \\ Kucharski Jean-baptiste ${ }^{1}$, Wilk Stanislas ${ }^{1}$
}

\begin{abstract}
1 Université de Bordeaux EPOC UMR 580533615 Pessac Cedex ,France
2 Department of Earth Science University of Bergen Allégaten 415007 Bergen ,Norway

3 IFREMER Géosciences Marines CS 10070, 29280 Plouzané, France

${ }^{4}$ Geological Survey of New Caledonia DIMENC BP 46598845 Nouméa New Caledonia ,France

${ }^{5}$ Centre Européen de Recherche et d'Enseignement de Géosciences de l'Environnement Aix-Marseille Université - CNRS (UMR7330) - IRD (UMR 161) - COLLEGE de France - USC INRA - OSU - Institut PYTHEAS - Technopole Environnement Arbois-Méditerranée BP80 13545 Aix en Provence Marseille CEDEX 04 ,France
\end{abstract}

* Corresponding author : Audrey Recouvreur, email address : audrey.recouvreur@gmail.com

\begin{abstract}
:
The large acoustic data set acquired during the Carambar cruises is composed of high resolution bathymetry, backscatter data and very-high resolution seismic lines which allow for an overview of the morphology and sediment transfer processes from the shallow upper slope to the abyssal plain of a modern carbonate system: the north-eastern slope of the Little Bahama Bank. Surficial distribution of the acoustic facies and echofacies reflects a wide variety of sedimentary processes along and across the slope. The western sector of the Little Bahama Bank is dominated by depositional processes whereas its eastern sector, which is incised in the lower slope by giant canyons, is affected by erosion and bypass processes. Datasets suggest that currents play an important role both along-slope sedimentary processes and in the abyssal plain. The Antilles Current appears to affect a large part of the middle and lower slopes. The absence of sizable present-day channel/levée complexes or lobes at the mouth of the canyon revealed by the bathymetric map - indicates that the southward flowing Deep Western Boundary Current influences modern abyssal sediment deposition. Based on depositional processes and indicators of canyon maturity observed in facies distribution, the current study proposes that differential subsidence affects the eastern versus western part of the bank. The morphology of the Great Abaco Canyon and Little Abaco Canyon, which extends parallel to the platform, and the Little Bahama Bank slope appears to be related to the Great Abaco Fracture Zone.
\end{abstract}

Keywords : Backscatter Bahamas, carbonate slope, echofacies, giant canyon, sea floor morphology, sedimentary processes 
59 Submarine canyons are structures incising the continental margins or shelves with a width and height of up 60 to several kilometres (Shepard \& Dill, 1966). Acting as catalysts of sediment export from shelves towards 61 the deeper basin via their steep flanks, submarine canyons are critical elements of basin sedimentary 62 deposits. Studies on submarine canyons have focused on siliciclastic systems (Babonneau et al., 2002; 63 Paull et al., 2013; Tubau et al., 2015), which are more attractive in terms of reservoir potential for 64 hydrocarbons. Recent industrial discoveries in carbonate slopes (Bertello et al., 2010; Busson et al., 2019) have boosted their attractiveness and hence have piqued the scientific interest of such systems. However, sedimentary processes affecting purely carbonate canyons, rivaling siliciclastic canyons in terms of size, and their impact on carbonate sediment transfers and sources remain poorly understood. The Little Abaco Canyon and especially the Great Abaco Canyon have only been briefly described in the past decades (Shepard \& Dill, 1966; Benson et al., 1978; Mullins \& Neumann, 1979; Mulder et al., 2018).

As the Bahamian carbonate platform is one of the best-known modern carbonate systems, the Carambar cruises have targeted its slopes and associated incising canyons. Previous Carambar (2010) and Carambar 1.5 (2014) oceanographic cruises imaged a large part of the Little Bahama Bank (LBB) northwest slope using multibeam echo-sounder data and very-high resolution seismic profiles (Fig. 1; Mulder et al., 2012a, 2014, 2017b). These studies have focused on: (i) the LBB periplatform drift, (Chabaud, 2016); (ii) the architecture of the slope canyons and mass transport complexes affecting the eastern LBB (Mulder et al., 2012a; Tournadour, 2015, 2017); (iii) the genesis and growth of the carbonate wedge along the LBB (Fauquembergue et al., 2018); and (iv) sediment transfers across the LBB slope (Tournadour, 2015; Fauquembergue, 2018). In order to provide a holistic view of the carbonate system, the consideration of the region as a whole has yet to integrate the complete study of the two main canyons present in the zone: the Great Abaco Canyon and the Little Abaco Canyon.

New high-resolution multibeam bathymetry, backscatter and very-high resolution seismic data acquired during the Carambar 2 (2016 to 2017) cruise enabled visualization of the eastern half of the slope of the modern LBB from shallow to deep environments (Fig. 1). The bathymetry of the eastern sector has highlighted the presence of two giant canyons previously described by Mulder et al. (2018): the Great Abaco Canyon (GAC) and the Little Abaco Canyon (LAC). The present study is based on a combination of acoustic data that provide a large-scale view of sedimentary distribution, something that is difficult to recognize if only using sedimentary data.

This approach allows the potential links between: (i) the sedimentary surface and subsurface processes; and (ii) slope structure to be highlighted. This paper explains that the connectivity of these elements is

90 based on carbonate transfer from the slope to the ultra-deep domain through potentially structurally 
controlled canyons. The work here also provides knowledge regarding giant purely carbonate canyons

92 which are disconnected from the platform, along with comprehensive elements on how they work both in

93 terms of source and transfer of carbonate material to the basin.

\section{REGIONAL SETTINGS}

\section{Physiography and oceanography}

96 The Bahamian platforms form an almost pure marine carbonate sedimentary system isolated from the 97 siliciclastic terrigenous continental input by deep channels and escarpments. Platforms, slopes and the 98 abyssal plain developed over a wide marine area (over $32000 \mathrm{~km}^{2}$ ) which is supplied by a tropical 99 carbonate factory (Schlager, 2005). The archipelago is located on the western margin of the Atlantic Ocean.

100 Covering more than $300000 \mathrm{~km}^{2}$, this archipelago is composed of more than 700 islands and is bordered by 101 the Blake Bahama Escarpment to the east (BBE; Buchan, 2000), the contouritic Blake Plateau (BP) to the 102 north, the Old Bahama Channel to the south and the Florida Strait to the west (Fig. 1). Several islands are 103 developed in the north and centre of the Bahamas on two large carbonate platforms, the Little Bahama 104 Bank (LBB) and the Great Bahama Bank (GBB) which are separated by the North-west Providence 105 Channel (Fig. 1).

The Little Bahama Bank is the second largest isolated platform in the Bahamas and is located in the northernmost part of the archipelago (Fig. 1). The north-western side of the slope is characterized by the 'Little Bahama Bank drift', a modern periplatform drift, mainly supplied by off-bank sediment transport from the near-by carbonate platform (Chabaud et al., 2016). The development of such carbonate drift in this particular location results from the combined action of currents and sediment supply (Mullins et al., 1980; Betzler et al., 2014; Tournadour et al., 2015; Chabaud et al., 2016). The north-eastern slope of the Little Bahama Bank is incised by two $163 \mathrm{~km}$ and $56 \mathrm{~km}$ long carbonate canyons, the Great Abaco Canyon (GAC) and the Little Abaco Canyon (LAC; Mulder et al., 2018), respectively, with their mouths opening to the Blake Basin and extending to the toe of the Blake Bahama Escarpment at $5000 \mathrm{~m}$ water depth (Fig. 2).

The physiography, sediment transport and deposition processes of the Bahamian carbonate platforms also depend on ocean circulation and currents. In particular, two main currents affect the Little Bahama Bank (Fig. 1): the Antilles Current and the Florida Current. The Antilles Current flows northward along the eastern side of the LBB and is composed of water coming from the south (Fig. 1). To the west of the LBB, the Florida Current also flows northward and is formed by waters from both the Caribbean Sea and the Gulf of Mexico. North of the Little Bahama Bank, at the exit of the Florida Strait, these two currents merge to form the Gulf Stream (Fig. 1; Neumann \& Pierson, 1966; Richardson, 1977). The Deep Western 
122 Boundary Current (DWBC; Fig. 1) is a deep current (1000 to $5000 \mathrm{~m}$ deep) flowing southward along the

$123 \mathrm{BBE}$ at about $70 \mathrm{~cm} / \mathrm{s}$ (Hollister \& Heezen, 1972). It corresponds to the deepest part of the North Atlantic

124 Deep Water (NADW; Meinen et al., 2004). Fauquembergue (2018) suggested that another current, the

125 Antarctic Bottom Water (AABW; Fig. 1) might have impacted the deeper part (>4800 m) of the study area

126 in the past, especially during glacial periods.

127 Climate

128 The climate in the Bahamas archipelago is tropical and bi-seasonal. Precipitation is abundant during 129 summer, while winters are dry, and the annual temperature average $c a 25^{\circ} \mathrm{C}$. The mean annual rainfall is $130857 \mathrm{~mm}$ and increases northward (Buchan, 2000). Hurricanes hit the archipelago from August to October 131 three times every four years on average (Buchan, 2000), and on average over the year, cold fronts affect it 13223 times (Hardy \& Henderson, 2003).

\section{Geological context}

134 The present day physiography of the Bahamas resulted from successive tectonic phases initiated by 135 Pangaea dislocation during the Jurassic (Duncan \& Hargraves, 1984; Engebretson et al., 1985; Ross \& 136 Scotese, 1988; Pindell, 1994; Meschede \& Frisch, 1998; Coates et al., 2004; James, 2009). The Bahamas 137 giant carbonate platform initiation began during Late Jurassic rifting with accumulation of shallow marine 138 deposits and evaporites until the Early Cretaceous (Austin et al., 1986; Sheridan et al., 1988). This giant 139 platform extended from the Blake Plateau to the Blake Bahama Escarpment where a reef system developed 140 (Sheridan et al., 1988) and allowed the development of the Little Bahama Bank (Sheridan \& Osburn, 1975; 141 Austin et al., 1986; Sheridan et al., 1988). The Atlantic crust was affected by fracture zones due to rifting 142 activity associated to the Pangaea Dislocation. In particular, regional magnetic data reveals the presence of 143 the Bahama Fracture zone or Great Abaco Fracture zone which affects the northern sector of the Bahamas 144 (Fig. 1; Sheridan \& Osburn, 1975; Benson et al., 1978; Mullins et al., 1982).

\section{Sediment exports}

146 Part of the offshore material exported from the platform is transported through dense hyperpycnal water 147 sinking in the ocean (Wilson \& Roberts, 1995). This process, called density cascading, is very efficient and 148 some high-density cascading events are able to transport coarse-grained sediment to the slope (Wilson \& 149 Roberts, 1995). Density cascading is strongly controlled by seasonal changes. In summer, heat and 150 moisture are parameters controlling processes such as evaporation, which can cause a slight increase in 151 salinity and therefore can trigger density-driven flows (Wilson \& Roberts, 1992, 1995). In winter, cold 152 fronts generate density disequilibrium between the shallow platform and ocean surface waters. Surface 
waters are cooled by the cold front, enhancing evaporation and increasing salinity, and ultimately leading to the sinking of dense post-cold front platform waters (Wilson and Roberts, 1992, 1995). During cold front events, the fine-grained, bank-derived material is exported by density cascading and deposited on the uppermost slope, forming the Holocene wedge (Fauquembergue et al., 2018).

During periods of major flooding of the Little Bahama Bank corresponding to sea-level highstands in the Late Pleistocene, off-bank transport was the main transport process from the carbonate bank to the slope ( Hine \& Neumann, 1977; Hine et al., 1981; Chabaud et al., 2016). The 'spin circle', a circular flow pattern induced by ebb and flood currents around shoals, promotes the accumulation of ooids in tidal deltas (Reeder \& Rankey, 2009; Mulder et al., 2017). Only fine-grained mud can be partially exported through the ebb-flood sediment transport (tidal flushing) that occurs predominantly after storms (Mulder et al., 2017). This sediment flushing supports off-bank transport: the fine bank-derived fraction, when mixing with pelagic production, leads to the formation of the periplatform ooze on the uppermost slope (Chabaud et al., 2016). Pelagic sedimentation is the predominant process at play in the study area, while the deposition of off-bank material is concentrated in the Little Bahama Bank drift (Fauquembergue, 2018).

\section{DATA AND METHODS}

The Carambar project aims at understanding the sediment transfer between the platform and the deep basin in a terrigenous-free carbonate environment. Leg 2 of the Carambar cruise (Fig. 1; November 2010 on the $R / V$ Le Surôtt) was dedicated to the study of the north-west slope of the Little Bahama Bank (Fig. 1; Tournadour et al., 2015, 2017a; Chabaud et al., 2016). Carambar 1.5 cruise (November 2014 on the $R / V$ F.G. Walton Smith) focused on the uppermost slope of the LBB (Fig. 1; Mulder et al., 2012a). The northeastern sector of the Little Bahama Bank slope and the abyssal plain, including the Great Abaco Canyon and Little Abaco Canyon, were studied during Leg 1 of the Carambar 2 cruise (December 2016 on the $R / V$ L'Atalante; Fig. 1; Mulder at al., 2018). Bathymetric and backscatter data from a Kongsberg EM302 (Carambar) (Kongsberg Group, Kongsberg, Norway), a Teledyne Reson Seabat 7125 (Carambar 1.5) (Teledyne Technologies Inc., Thousand Oaks, CA, USA) and a Kongsberg EM122/EM710 (Carambar 2), as well as Very High Resolution (VHR) (Chirp) and high resolution seismic data from four air guns and a 192-channel streamer were acquired simultaneously during each cruise covering more than $24650 \mathrm{~km}^{2}$ (Fig. 1). The multibeam echo-sounders are characterized by a transmission frequency operating between 50 $\mathrm{m}$ and $12000 \mathrm{~m}$ depth. This allows the simultaneous acquisition of: (i) bathymetric data based on the calculation of the round-trip time of the emitted acoustic waves; and (ii) acoustic reflectivity, a function of the intensity of the backscattered signal dependent on the lithology of superficial sediments (i.e. nature and induration/lithification). The bathymetric data were cleaned of aberrant probes with the CARAIBES software (@Ifremer) and the reflectivity data were compensated for signal directivity with the SonarScope 
software (OIfremer, Augustin \& Lurton, 2005). These data were then gridded to obtain bathymetric and acoustic reflectivity maps with a spatial resolution of $25 \mathrm{~m}$ (Carambar 1 and Carambar 1.5) to $50 \mathrm{~m}$ (Carambar 2).

Gravity cores with a length ranging between 1 to $11 \mathrm{~m}$ were also recovered with a Kullenberg coring system. During the three cruises, the 'Chirp' sub-bottom profiler provided more than $5496 \mathrm{~km}$ of VHR seismic profiles penetrating up to 60 to $80 \mathrm{~ms}$ two-way travel time. The definition of seismic facies was based on these datasets, using backscatter, geometry, amplitude and continuity of the seismic reflections to establish a facies classification. To facilitate the exploitation of this large dataset, morphological and sedimentological structures were defined according to a backscatter classification based on acoustic facies and a VHR seismic classification based on echofacies.

Changes in backscatter values correspond to variations in nature, texture and state of the sediments and/or the sea-bed morphology (Hanquiez et al., 2007, 2010; Principaud et al., 2018) while the VHR seismic profiles reveal(s) subsurface geometry characteristics and small-scale morphology (for example, seafloor rugosity). For the acoustic facies, the categories are based on the amplitude of the reflectivity and on the patterns observed. For the echofacies, the categories are based on the amplitude and geometry of the reflectors. These classifications provide information regarding seafloor and subsurface sedimentological parameters. Studies in siliciclastic (Damuth \& Hayes, 1977; Damuth, 1980; Hanquiez et al., 2007, 2010) and carbonate environments (Mullins \& Neumann, 1979; Mullins et al., 1984; Tournadour, 2015; Principaud et al., 2018) linking echofacies and lithology provide a basis for interpreting these echofacies in terms of depositional environments and allows for calibration of interpretations. The association of acoustic facies, echofacies and morphobathymetry were integrated in a general classification of sedimentary facies (Table 1). Various spatial analyses and maps were produced using ArcGIS for Desktop software (@Esri).

\section{RESULTS}

\section{Little Bahama Bank slope, Great Abaco Canyon and Little Abaco Canyon morphology}

The north slope of the Little Bahama Bank can be subdivided in four parts according to slope morphology (Fig. 2A to C). These subdivisions are based on previous work (Rankey \& Doolittle, 2012; Tournadour, 2015) and redefined considering the new bathymetric data provided by the Carambar 2 cruise which evidence a steeper slope than the previous domains. These redefined subdivisions were introduced to assure the homogeneity and logical continuity of domains from the eastern and western sectors of the study area (Fig. 2C). The adapted domains reflect the morphology of both the western and eastern sides of the Little Bahama Bank slope. 
2171 The uppermost slope extends from the platform edge to 240 to $300 \mathrm{~m}$ water depth. It is relatively 218 smooth, constitutes the steepest $\left(>15^{\circ}\right)$ slope of the LBB and includes a sediment wedge (Fig. 2A to C; 219 Mulder et al., 2012b; Fauquembergue et al., 2018). This wedge can reach up to $35 \mathrm{~m}$ in thickness, is mainly 220 Holocene in age and is separated from the platform by four 10 to $20 \mathrm{~m}$ deep and $50 \mathrm{~km}$ wide terraces 221 (Mulder et al., 2012b; Fauquembergue et al., 2018).

2222 The upper slope extends from 240 to $300 \mathrm{~m}$ to $650 \mathrm{~m}$ water depth. It has a gradient of 1 to $2^{\circ}$ and is 223 incised by slope canyons (Fig. 2A to C). Only the linear part of these canyons is included in this slope 224 sector. A mass transport complex (MTC) was described by Tournadour et al. (2015) in its westernmost part 225 (Fig. 2).

2263 The middle slope extends from 650 to $1000 \mathrm{~m}$ water depth and its gradient increases from $1^{\circ}$ in the west 227 to 3 to $4^{\circ}$ in the east (Fig. 2A to C). This slope is incised by the slope canyon (Fig. 3A). Bathymetric highs 228 followed by depressions represent slide scars. They affect the part of the slope situated between the 229 canyons all along the slope. Other structures such as carbonate mounds and pockmarks are situated in the 230 western part of the middle slope (Fig. 3B).

2314 The lower slope extends from 1000 to $1500 \mathrm{~m}$ water depth with a gradient increasing towards the 232 abyssal plain from 0.6 to $4^{\circ}$ (Fig. 2A to C). In this part of the slope, several structures can be observed. 1 to $23320 \mathrm{~m}$ deep straight, parallel furrows affect the seafloor mostly in the west (Fig. 4A). Other erosional 1 to 10 234 m deep furrows oriented N300 to N270 cross-cut the former furrows and extend eastward (Fig. 4A). Both 235 types of furrows extend over several kilometres and are spaced hundreds of metres apart. Undulated 236 structures with a $5 \mathrm{~m}$ amplitude can be observed on the seafloor upstream of the Little Abaco Canyon (Fig. 237 4B). In the northern part of the study area, the Blake Plateau dips towards the east with a gradient of $0.5^{\circ}$ 238 between $\mathrm{ca} 1200$ to $1600 \mathrm{~m}$ water depths. Mass movements, which are evidenced by scars ('S'; Fig. 4C), 239 gullies and a valley leading to the Great Abaco Canyon also dissect this plateau.

240 The Great Abaco Canyon and Little Abaco Canyon are U-shaped (with a length of $163 \mathrm{~km}$ and $56 \mathrm{~km}$ 241 respectively; Fig. 5A). These two canyons are punctuated by knickpoints and outsized chutes (Fig. 5C and 242 D). These chutes are over $500 \mathrm{~m}$ high and are followed by $279 \mathrm{~m}, 113 \mathrm{~m}$ (LAC), $150 \mathrm{~m}, 140 \mathrm{~m}$ and $113 \mathrm{~m}$ 243 (GAC) depressions called plunge pools (Figs 5A, 5B, 6A and 6B; Mulder et al., 2018). The GAC and LAC 244 are parallel to the LBB edge and are aligned with the Great Abaco Fracture Zone (GAFZ), whereas the 245 upper and middle slope of the LBB are affected by canyon incisions which are perpendicular to the margin. 246 South of the Great Abaco Canyon, a relict plateau situated at $1000 \mathrm{~m}$ water depth displays evidences of 247 mass movement ('S'; Fig. 4C) and is incised by two valleys. Twenty kilometres away from the Great 
248 Abaco Canyon and $7 \mathrm{~km}$ south of the Little Abaco Canyon, two $5 \mathrm{~km}$ long canyons incise the Blake

249 Plateau and the slope through the Blake Bahama Escarpment, respectively (Fig. 2A).

The south-east limit of the plateau consists of the SSW-NNE oriented Blake Bahama Escarpment 251 (Fig. 2). This feature is a $2000 \mathrm{~m}$ high and $60^{\circ}$ steep escarpment. It separates the Blake Plateau from the 252 Atlantic Abyssal Plain lying at $4900 \mathrm{~m}$ water depth. The bathymetry shows $50 \mathrm{~km}$ long chaotic deposits 253 extending over $20 \mathrm{~km}$ away from the escarpment [mass wasting deposits (MWD); Fig. 2A]. A more than $254200 \mathrm{~m}$ thick sediment bulge extends at the mouth of the Great Abaco Canyon in the abyssal plain.

\section{Acoustic facies}

256 The identification of acoustic facies is based on the intensity of the backscatter and the patterns of 257 reflections observed inside (Fig. 7). In this work, the darkest colours correspond to high-reflectivity 258 (implying either coarse sediments, indurated sediments or both) and lighter colours correspond to low 259 reflectivity (finer and softer sediments). In the study area, backscatter tones can be subdivided into eight categories (Table 2; Fig. 8).

2611 The very high-reflectivity homogeneous acoustic facies is observed only in few parts of the study area. 262 This the acoustic facies is found: (i) at the toe of the Blake Bahama Escarpment; (ii) in the $5 \mathrm{~km}$ long canyon in the northern sector of the Great Abaco Canyon; (iii) in the steepest part of the Great Abaco 264 Canyon; and (iv) in the flanks of the Little Abaco Canyon (Fig. 8). In the western sector of the study area, this facies makes up: (i) the uppermost slope; (ii) the area upstream from the small canyons; as well as (iii) the edge of the scars between canyons.

2 The very high-reflectivity heterogeneous acoustic facies (Table 2) is characterized by alternation of very-high reflectivity and patches of high reflectivity. It is associated with the main part of the flank of the Blake Bahama Escarpment and both sides of the Great Abaco Canyon (Fig. 8).

3 The high-reflectivity homogeneous acoustic facies covers a large part of the upper slope and proximal part of the abyssal plain (Fig. 8). It was evidenced between the canyons that incise the western part of the upper slope, and in the MTC structure on the eastern sector as well as on the Blake Plateau. This facies also corresponds to a part of the flank of the Blake Bahama Escarpment and the deposits contiguous to the Blake Bahama Escarpment between the Little Abaco Canyon and the Great Abaco Canyon and north of the

4 The high-reflectivity heterogeneous acoustic facies corresponds to high-reflectivity with medium reflectivity lineations of two types: (i) lineations extending from the canyons in the western part of the slope and the valley feeding the giant canyons; and (ii) N300 to N270 oriented lineations in the eastern 
279 Little Bahama Bank lower slope (Tournadour, 2015). This area also covers a part of the relict plateau

280 between the Great Abaco Canyon and the Little Abaco Canyon (Fig. 8).

2815 The medium homogeneous reflectivity acoustic facies is the most frequent acoustic facies encountered 282 in the study area. It covers the abyssal plain, the canyons incising the upper slope, the smooth parts of the 283 middle slope and the western part of the study area including the smooth parts of the Blake Plateau at the 284 lower slope.

2856 The medium patchy heterogeneous reflectivity acoustic facies corresponds to medium reflectivity with 286 patches of high reflectivity. It is present at the transitions between high acoustic facies and medium 287 acoustic facies in the lower slope (Fig. 8).

$288 \quad 7$ The medium undulated heterogeneous reflectivity acoustic facies is characterized by medium reflectivity 289 with high-reflectivity undulated structures. It is mostly present in the western part of the slope and corresponds to the transition between the furrows of different slope canyons (Fig. 8).

2918 The medium punctuated heterogeneous reflectivity acoustic facies is characterized by medium 292 reflectivity with small circular patches of high reflectivity with a diameter of 100 to $200 \mathrm{~m}$. It covers a large part of the relict plateau between the Great Abaco Canyon and the Little Abaco Canyon, areas at the end of the furrows in the western part of the study area and some parts of the Blake Plateau (Fig. 8).

\section{Echofacies mapping}

297 The VHR seismic mapping was realized using an echofacies classification based on the amplitude and the geometry of the seismic signal (Table 3). Five echofacies can be defined in the study area (Table 3; Fig. 9).

1 The bedded echofacies covers the majority of the western part of the upper slope (unaffected by 300 canyons), the uppermost slope wedge, the sediment over the MTC, the part without slides of the Blake 301 Plateau and the northern part of the deep basin, at the mouth of the Great Abaco Canyon (Fig. 9). It is found predominantly in areas with a gentle slope $(\leq 1)$.

2 The hyperbolic echofacies occurs where the slope is steeper, when the slope abruptly changes, in the canyons incising the upper slope, in the Great Abaco Canyon and Little Abaco Canyon, in the $5 \mathrm{~km}$ long canyons C1 and C2 (Figs 2 and 9), and on the Blake Bahama Escarpment and its associated deposits (Fig. 9). 
3 The blind echofacies is the least developed of the facies. It corresponds to the shallower part of the uppermost slope of the study area and appears sparsely in the Blake Bahama Escarpment and on plane surfaces of the Blake Plateau. It also covers the smooth areas separating the furrows on the western lower 310 slope.

3114 The combined I (hyperbolic + blind) echofacies corresponds to slightly diffuse bedded reflections with 312 hyperboles. This facies covers two major parts of the study area: (i) the southern part of the basin at the 313 mouth of the Little Abaco Canyon; and (ii) the western part of the study area in the lower slope 314 corresponding to the mouths of the slope canyons (Fig. 9). This last part overlaps the furrows and the N300 315 lineations affecting the seafloor. Combined I echofacies covers an important part of the head of the Great 316 Abaco Canyon. It also appears more locally upstream of failure scars that cover part of the Blake Plateau.

5 The combined II (hyperbolic + bedded) echofacies corresponds to bedded reflections overlying the 318 hyperboles. It appears mainly in the tributaries feeding the Great Abaco Canyon and the Little Abaco 319 Canyon as well as on the flanks of the Great Abaco Canyon (Fig. 9). This echofacies is also present in the 320 canyons of the east upper slope, in patches on the Blake Plateau, in the mass wasting deposits and in the eastern part of the basin.

The combined study of bathymetry, acoustic facies and echofacies compared with previous studies (Hanquiez et al., 2007, 2010; Tournadour, 2015; Principaud et al., 2018) allowed for the definition for different domains, which are each associated with different processes (Table 1; Figs 10, 11 and 12A).

\section{INTERPRETATIONS AND DISCUSSION}

\section{Sedimentary processes along the northern Little Bahama Bank slope}

\section{Depositional processes}

Hemipelagic and contouritic deposits.

In the western part of the study area, the slope is characterized by overall homogeneous, medium reflectivity acoustic facies and bedded echofacies. This facies corresponds to deposits linked to the export of carbonate mud from the platform (facies 1, Figs 11 and 12B; Tournadour et al., 2015), as well as contourite deposits which characterize the Little Bahama Bank drift (Chabaud, 2016). Both hemipelagic and contouritic deposits are susceptible of producing this facies as they promote the deposition of finegrained sediment (medium homogeneous reflectivity) with low impedance contrast (bedded echofacies). Furthermore, the size scale of the LBB drift is such that its geometries are not visible at the resolution of this study. The presence of such acoustic facies over the MTC suggests that it is covered by a hemipelagic 
blanket. This mainly medium homogeneous reflectivity zone with smaller medium heterogeneous patchy reflectivity facies zone are associated with hyperbolic echofacies. The hyperboles are likely related to the steep edges of the dome shape geometry and thus highlight the presence of deep-water carbonate mounds (facies 2, Fig. 11; Tournadour et al., 2015).

This facies association also appears in other regions of the study area like the Blake Plateau or the plateau situated between the Little Abaco Canyon and the Great Abaco Canyon (Fig. 11). It corresponds to flat areas suggesting hemipelagic sedimentation (facies 1, Fig. 11).

\section{Periplatform ooze.}

345 The uppermost slope is characterized by blind echofacies, followed downslope by bedded echofacies 346 associated with medium reflectivity which correspond to a Holocene sediment wedge and the terraces 347 overhanging it (Figs 8 and 9; Rankey \& Doolittle, 2012). The homogeneous and medium homogeneous 348 nature of the reflectivity in this area suggests the presence of soft, fine-grained, bank-derived sediment 349 mixed with pelagic production. The presence of these acoustic facies and the bedded echofacies is 350 consistent with periplatform ooze deposits in the uppermost slope (facies 3, Fig. 11). Echofacies located on 351 the uppermost and upper slope correspond to bank-derived sediments, while bedded echofacies located on the northern Blake Plateau correspond to contouritic and pelagic blankets (Fauquembergue, 2018).

Turbiditic deposits.

A $c a 3 \mathrm{~km}$ large circular-shaped structure, represented by combined blind and hyperbolic echofacies and homogeneous medium-reflectivity acoustic facies, can be observed in the eastern part of the lower slope, in the downslope extension of the canyons (Fig. 4B). The analysis of a sediment core located in this feature revealed coarse-grained sediments with a relatively high sedimentation rate $(12 \mathrm{~cm} / \mathrm{kyr}$; Fauquembergue, 2018). It is suggested in this study that this structure corresponds to a lobe deposited at the mouth of a 10 $\mathrm{km}$ long canyon (Fig. 4B). In addition, $5 \mathrm{~m}$ amplitude structures extending over $4 \mathrm{~km}$ over this lobe can be interpreted as sediment waves (Fig.4B). Here, sediment waves refer to a generic term to describe undulated features since the resolution does not provide any further information regarding their nature (dunes, cyclic steps, etc). This lobe fills a small depression and its volume can be estimated to $240 \times 10^{6} \mathrm{~m}^{3}$ (Fauquembergue, 2018). It implies recent activity of sediment transport through the slope canyon to the head of the Little Abaco Canyon and highlights the modern activity of the eastern slope canyons. It also suggests turbidity flows and export activity upstream of the Little Abaco Canyon (facies 4, Fig. 11).

Base of slope deposits.

On the lower slope of the western part of the study area (Fig. 11), downstream of the canyons and furrows, medium reflectivity punctuated facies is associated with bedded and blind echofacies and displays a fan- 
shaped structure. The association of both medium reflectivity and bedded echofacies implies that sediment dynamics are dominated by depositional processes. The presence of high amplitude reflectors which overlie diffuse reflectors associated with higher reflectivity suggests the presence of more indurated or coarsergrained sediments than the hemipelagic blanket observed westerly. Therefore, this association also suggests low deposition rates and/or slight induration of those grainy deposits (facies 5, Fig. 11).

Mass wasting deposits.

On the Blake Bahama escarpment and $20 \mathrm{~km}$ eastward in the basin, hyperbolic echofacies and homogeneous, very high to high reflectivity acoustic facies co-occur with $50 \mathrm{~km}$ long chaotic deposits extending over the escarpment. These chaotic deposits were interpreted as mass wasting deposits originating from stacking events of the mass movement of hundreds of metres thick sediments from the Blake Bahama Escarpment (Mulder et al., 2018). The high reflectivity and hyperbolic echofacies suggests that the chaotic deposits are indurated and coarse-grained, probably blocky, and of considerably large size (facies 6, Figs 11 and 12B). These deposits could correspond to calciturbidites or calcidebrites as observed in Exuma Sound (Reijmer et al., 2012). The hyperbolic echofacies suggests that these deposits accumulated with steep edges or contain blocks of consequent size. These chaotic deposits are separated on both sides of the Great Abaco Canyon by a large band of bedded echofacies associated with homogeneous, mediumreflectivity (Figs 8 and 9).

At the mouth of the Little Abaco Canyon, the hyperbolic facies is associated with homogeneous and heterogeneous high-reflectivity acoustic facies extending $8 \mathrm{~km}$ away from the canyon. This facies association suggests that hard and/or coarse-grained sediments form the lobe at the mouth of the Little Abaco Canyon (Fig. 4D).

Mass wasting events originating from the Blake Bahama Escarpment likely accounted for a significant portion of the sediment supply towards the basin. Conversely, the Great Abaco Canyon likely contributed to a minor extent as a sediment source, since no erosion or depositional (lobe) structures were evidenced by bathymetric survey at its mouth. At the mouth of the Little Abaco Canyon, four 50 to $100 \mathrm{~m}$ high knickpoints can be observed within the mass wasting deposits. This suggests recent or important canyon activity resulting in the formation of supercritical flows which lead to the development of hydraulic jumps (Komar, 1971). In turn, these hydraulic jumps produce knickpoints and, ultimately, contribute to maintaining the fresh appearance of the knickpoints (Guiastrennec-Faugas et al., 2020).

Abyssal plain deposits.

Homogeneous medium reflectivity acoustic facies cover the Blake Bahama abyssal plain and are associated with bedded echofacies in the north or combined I reflectivity in the south. This implies that they are made 
401 up of fine-grained or slightly indurated sediments (facies 7, Fig. 11). Regardless of sediment nature, VHR

402 seismic data shows thin-bedded reflections over a high amplitude reflection that could correspond to

403 basaltic oceanic crust, suggesting a thin sediment cover.

$404 \quad$ Erosion and bypass processes

405 Hardgrounds.

406 The western part of the upper slope and the central part of the middle slope are characterized by 407 homogeneous high-reflectivity acoustic facies separated by strips of homogeneous medium reflectivity.

408 These facies are respectively associated with bedded and hyperbolic echofacies and are likely connected to 409 the numerous 2 to $20 \mathrm{~km}$ long canyons and the inter-canyon plateaus (facies 8 and 9, Fig.11). The presence 410 of the hyperbolic facies is consistent with the abrupt change of slope gradient on the canyon edge walls and 411 the reflection of the acoustic signal. The homogeneous high-reflectivity acoustic facies combined with the 412 bedded echofacies is restricted to the smooth part of the inter-canyon slope. The high-reflectivity acoustic 413 facies indicates low penetration of the acoustic signal in the sediments in this area and are consistent with 414 the high-amplitude bedded reflections. This could imply early cementation (facies 10, Fig. 11). The 415 analysis of core CARKS26, located at the base of the middle slope (Fig. 2A), shows periplatform ooze 416 deposits containing indurated nodules corresponding to a facies described by Tournadour (2015) and 417 Chabaud (2016) as the nodular ooze facies (facies 9, Fig. 11). It suggests an induration gradient 418 (Tournadour et al., 2017) and bypass transport along the smoothest part of the slope, reflected by an 419 increase in reflectivity intensity down the slope.

Between $78^{\circ} 24^{\prime} \mathrm{W}$ and $77^{\circ} 21^{\prime} \mathrm{W}$, the lower slope shows an irregular surface characterized by a heterogeneous, high-reflectivity acoustic facies with medium reflectivity lineations (Fig. 8) associated with a combination of bedded, blind and hyperbolic echofacies. This area displays furrows extending from the 423 canyons, eroding the slope and finally gently bending eastward (Figs 2A and 4A) in the slope direction.

424 Both high reflectivity and the blind part of the echofacies suggest an induration of this part of slope that could be related to the presence of furrows (facies 10, Figs 11 and 12B). This suggests down-slope gravitational processes (facies 10, Figs 11 and 12B). These structures are cross-cut by perpendicular erosional furrows, oriented N300 to N270 (Fig. 4A) that are interpreted as the results of the action of either the northward flowing Antilles Current or the southward flowing Labrador Current (upper part of the DWBC). These furrows related to medium reflectivity lineation are responsible for the hyperbolic component of the combined echofacies. 
432 The cover of the MTC present in the western sector of the study area is associated with homogeneous, 433 medium-reflectivity acoustic facies and bedded echofacies while its edge is composed of homogeneous 434 very high-reflectivity facies (facies 12 , Fig. 11). The very high-reflectivity facies is likely related to the 435 steep and indurated walls of the MTC.

The lower slope of the Blake Plateau corresponds mainly to bedded, hyperbolic and combined echofacies linked respectively with homogeneous medium-reflectivity or high-reflectivity and heterogeneous medium-reflectivity facies. No slump scars were evidenced in the large flat area of the contouritic plateau suggesting that it is not affected by mass movement and is covered with bedded echofacies and homogeneous medium reflectivity acoustic facies. This suggests a lesser induration (Hanquiez et al., 2007, 2010; Principaud et al., 2018) of the sediment (facies 1, Fig. 11). These scars that affect the contouritic Blake Plateau can be related to sliding motion (facies 11, Fig. 11). The scars cause heterogeneities in reflectivity and are responsible for the variety of the combined facies which is expressed in reliefs and hyperbolae generated by failure scars in a generally bedded system. In addition, the highreflectivity of these facies suggests a higher state of induration, especially on the slide edges. The highreflectivity lineations in this zone are similar to the N300 to N270 lineations. High-reflectivity affects the edge of the Blake Plateau, suggesting erosion and/or bypass by bottom currents (DWBC or Antilles Current).

Based on bathymetry, Mulder et al. (2018) proposed that slide scars observed on the southern side of the relict plateau might be circumstantial evidence of a lateral supply of sediment to the Little Abaco and the Great Abaco Canyons. This study's results are consistent with these observations, as heterogeneous, medium-reflectivity facies with medium reflectivity patches are associated with bedded echofacies corresponding to flat areas. This association suggests hemipelagic sedimentation with no movements (facies 1, Fig.11). On the contrary, combined and hyperbolic echofacies are associated with highreflectivity heterogeneities oriented towards the Little Abaco and Great Abaco Canyons. These facies correspond to a relict contouritic plateau affected by numerous slides inducing a downslope sediment motion towards both the Little Abaco Canyon and the Great Abaco Canyon (facies 11 and 13, Figs 11 and 12B).

Heterogeneous, medium-reflectivity acoustic facies are associated with hyperbolic echofacies and abrupt changes in the slope upstream of the Little Abaco Canyon. The hyperbolic echofacies is related to intense sliding in this area, while the high reflectivity suggests coarse-grained or more indurated deposits.

462 The volume of sediment originated from slides appears to be more important at the toe of the northern flank 463 of the Great Abaco Canyon than on its southern flank, suggesting that the sliding source comes 
preferentially from the Blake Plateau located north of the Great Abaco Canyon (Fig. 12B). A strip of combined (bedded and hyperbolic) echofacies and heterogeneous, medium-reflectivity acoustic facies, in the south of the Little Abaco Canyon, likely corresponds to a terrace and suggests less indurated sediments (since the bedded part of the facies indicates deposition processes).

Slope canyons.

In the eastern part of the slope, the spacing between slope canyons of the same size scale is less regular. This part of the slope is affected by mass movements and scars that could evidence sliding (Fig. 13A). The canyons correspond to medium homogeneous reflectivity facies associated with combined hyperbolic echofacies due to the reflection of the acoustic signal on the steep canyon edge walls (facies 8, Fig. 11).

The eastern inter-canyon slope is associated with high homogeneous reflectivity, which suggests early cementation as in the western part of the slope (facies 9, Fig. 11). The smooth part of the inter-canyon plateaus, as observed on the western part of the study area, is represented by bedded and combined I (hyperbolic + bedded) echofacies. The hyperboles observed are due to the steep walls of the slide scars affecting the canyons and inter-canyon parts of the slope.

The association of heterogeneous high-reflectivity acoustic facies with combined I echofacies and erosive lineations characterizes the valley feeding the head of the Great Abaco Canyon. These facies suggest that the sediments covering the seafloor of the Great Abaco Canyon head are indurated or coarsegrained (facies 10, Figs 11 and 12B). The narrow head and the erosion structures suggest that the canyon head does not represent the main source of modern sediments settling in the canyon. The two other tributaries draining the south-eastern part of the slope are characterized by a combined II echofacies and homogeneous medium reflectivity, suggesting less-indurated deposits and a depositional tendency (facies 13, Figs 11 and 12B). The Great Abaco Canyon flanks and floor are associated with combined and hyperbolic echofacies as well as patches of medium to very-high reflectivity. This suggests the existence of both erosional and depositional processes in the canyons. It also suggests that mass movements affect the canyon edges and contribute to supplying downslope transport processes (Fig. 12B). This observation is consistent with the presence of terraces interpreted as originating from slumped masses in canyon-head amphitheatres (Mulder et al., 2018)

The two $5 \mathrm{~km}$ long canyon ( $\mathrm{C} 1$ and $\mathrm{C} 2)$ bodies and mouths incising the Blake Plateau and crossing the BBE are covered with hyperbolic echofacies associated with very-high reflectivity and high-reflectivity facies (facies 14, Fig. 11). This suggests the presence of indurated deposits and implies that the sediments transiting through them do not accumulate at the mouths of these canyons. 
496 Sediment distribution and transport along the Little Bahama Bank slope

497 Sediment export along the Little Bahama Bank slope is strongly controlled by the morphology of the

498 platform and the related hydrodynamic processes. This results in a complex distribution of sediments.

499 Difference between the eastern and western sectors of the LBB slope

500 In the western sector of the LBB, the deposition of fan-shaped deposits are due to sediment flows forming 501 furrows (Tournadour et al., 2017) and spreading out at the base of the slope (facies 5, Fig. 11). Different 502 processes seem to occur in the eastern sector of the LBB. Distributary furrows extend from the eastward 503 canyons situated between Bahama Bay and Spanish Cay (Fig. 12B) but fan-shaped base of slope deposits 504 do not exist at their mouth (Fig. 12B). The presence of sediment waves and lobate structures (facies 4, Fig. 505 11) filled with coarse-grained material suggests that turbiditic flows transit through the eastern canyons. On 506 the contrary, those transiting troughs the western canyons terminate in relatively finer-grained deposits 507 (facies 5, Fig 11). Thus, it is interpreted that low-density flows cut across the western canyons while 508 relatively higher density flows go through the eastern canyons (Fig. 12B).

In addition, the presence of medium homogeneous reflectivity facies at the toe of the eastern 510 canyons is generally indicative of less-indurated sediment than in the western part of the LBB which 511 displays medium reflectivity facies punctuated with high reflectivity zones (Fig. 8). These spatial 512 disparities in the acoustic facies implies different activity of the eastern versus western canyons. 513 Accordingly, the presence/absence of hemipelagic deposits and base of slope deposits are reliable criteria 514 which delimited the western and eastern part of the Little Bahama Bank slope (Fig. 12B).

\section{Sediment transit through Little Abaco and Great Abaco Canyon}

516 The presence of levee-shaped deposits between the two major Great Abaco Canyon tributaries indicate that 517 dilute turbidity currents supply much of the sediment (Mulder et al., 2018). This is consistent with the 518 homogeneous medium-reflectivity facies which suggests that sediment deposit and modern active sediment 519 processes occur in the eastern canyons.

Upstream of the head of the Great Abaco Canyon, bypass processes are reflected by high 521 heterogeneous and combined blind and hyperbolic facies and are associated to a hardground facies (facies 522 10, Fig. 11). This suggests that sediments pass through the Great Abaco Canyon and are not deposited on 523 its head. Considering the small size of the canyon head, the small number of slide scars (Fig. 13A) and the 
low-density currents supplying the western lower slope (Fig. 12B), this suggests less dense sediment supply transiting from its head (Fig. 12B).

Upstream of the Little Abaco Canyon, the acoustic set defining the turbiditic deposits (facies 4 , Table 3) imply that the eastern canyons are highly active. The acoustic set also suggests a direct axial 528 supply of the Little Abaco Canyon by relatively high-density turbidity currents. It further highlights the 529 supply difference between the Little Abaco Canyon and the Great Abaco Canyon.

North of the study area, $300 \mathrm{~km}$ away on the Blake-Bahama Outer Ridge region, erosional furrows

Spatial disparities in sediment processes and canyon maturity along the northern slope of the Little were observed by Hollister et al. (1974) at 4 to $5 \mathrm{~km}$ water depth and interpreted as the action of contour current activity. Previously conducted surveys show activity of the DWBC at $26.5^{\circ} \mathrm{N}$ (Lee et al., 1996; Bryden et al., 2005; Johns et al., 2005). In addition, the acoustic set associated with the abyssal plain deposits (facies 7, Fig. 11) suggests slight induration of these deposits. Thus, the DWBC impact on the material transiting through the canyon mouths cannot be neglected because it could have led to the presentday absence of topography and visible sediment accumulation at the mouth of the Great Abaco Canyon (Fig. 12B). Bahama Bank

The difference in the sediment flows transiting through the western versus eastern canyons emphasizes the existence of spatial disparities in deposition processes along the Little Bahama Bank slope (Fig. 14B). The western sector of northern slope of the LBB generally displays acoustic facies that are indicative of depositional facies such as hemipelagic deposits (facies 1, Fig. 11), periplatform oozes (facies 3, Fig. 11) or base of slope deposits (facies 5, Fig. 11). Especially in the westernmost part of the slope, sediment processes are dominated by almost entirely deposition processes (facies 1, 3 and 5, Fig. 11). On the contrary, the eastern sector displays more heterogeneous reflectivity facies and combined echofacies (Figs 8 and 9) suggesting the occurrence of erosional and/or bypass processes such as hardgrounds (facies 9 and 10, Fig. 11), slides (facies 11, Fig. 11) and escarpments (facies 13 and 14, Fig. 11), particularly on the middle slope and the part of the lower slope south of the GAC. Only the easternmost facies (facies 1, Fig. 11) and very localized turbidite deposits (facies 3, Fig. 11) depict the influence of local depositional processes. This spatial repartition of sediment/deposition processes is also highlighted by the spatial evolution of the slope canyons. As previously observed on the western part of the LBB slope (Tournadour, 2015; Mulder et al., 2017), a gradient in the maturity of the canyons can be observed between the western and eastern sectors of the study zone. The morphology of the eastern canyons presenting an amphitheatre shape (amphitheatre head highlighted by dotted lines in Fig. 13B) and an up dip linear part (Figs 3A and 
13B) likely corresponds to a mature stage of canyon formation on this slope (Puga-Bernabéu et al., 2011). Failure scars and more linear canyons can be observed in the central and western sectors and correspond to the retrogressive phase of the Little Bahama Bank slope canyon formation model. This holistic investigation of the LBB has enabled the mapping of sediment facies in the area, evidencing spatial disparities in sediment/depositional processes which ultimately denote an east-west canyon maturity gradient.

\section{Structural influence on Little Bahama Bank slope morphology}

While most canyons extend perpendicularly from platform edges, both the Great and Little Abaco canyons are oriented parallel to the edge of the LBB. The particular direction of these two major canyons coincides with the Great Abaco Fracture Zone (GAFZ in Fig. 1), suggesting that this structural feature controls canyons formation and persistence on the LBB slope. The influence of the Great Abaco Fracture Zone extends over the entire slope of the Little Bahama Bank as evidenced by: (i) the giant canyons which play an important part in sediment distribution; (ii) a marked east/west difference in platform morphology; and (iii) an east-west gradient in sediment and deposition processes, as well as a canyon's maturity. Spatial disparities in sediment processes were evidenced in this paper in the entire study area, completing previous observations which focused on the western sector of the LBB slope. The presence of abundant failure scars and more mature and linear canyons in the eastern sector of the LBB slope indicates that incisions are concentrated in this sector. This could be the result of slope steepening due to fault motion of the Great Abaco Fracture Zone. This motion generates differential subsidence between the eastern and western sectors of the Little Bahama Bank slope, while the edges of the Great Abaco Island define the axis of this motion. Furthermore, spatial discrepancies in the expression of differential subsidence (i.e. a steeper slope, sliding motion and the generation of giant canyons in the east, versus a gentler slope, and drift and hemipelagic deposition in the west) is indicative of a weaker direct structural influence in the western part of the northern Little Bahama Bank slope.

Thus, this east/west gradient imply that the inception of differential subsidence was likely linked to the development of the Great Abaco Fracture Zone. However, further analysis of high-resolution seismic lines would be necessary to assess the role played by the Great Abaco Fracture Zone in moulding the morphology of the Little Bahama Bank slope.

\section{Little Bahama Bank northern slope morphology and sediment processes: more general implications}

The presented multi-tool survey has provided a holistic view of the large $\left(325 \mathrm{~km} \mathrm{long} / 24650 \mathrm{~km}^{2}\right)$ sedimentary system that is the LBB, improving understanding of this system, and allowing a representation of the complete sedimentary profile from the carbonate shelf edge to the abyssal plain. This work evidences 
large-scale morphological characteristics and sediment dynamics of an entire carbonate margin from the shallow upper slope to deeper environments and identified preferential accumulation, bypass and erosion locations of the carbonate material on the slope. This study's work further highlights the mixed influence of both pre-existing structural features and sediment dynamics that may occur in a carbonate system such as the LBB. It provides new lines of investigation with regard to the genesis of giant carbonate canyons. The results suggest that these systems are structurally generated and moulded over time, with a strong influence of structural features on 'classic' slope canyon maturity. This has a major impact on carbonate stratigraphic modelling and carbonate seismo-stratigraphic interpretations in ancient analogue carbonate systems. Future acquisition of high-resolution seismic profiles in the area may provide further information regarding the timing of structural effects of the GAFZ on the northern sector of the Bahamas and their implication on the establishment of the Great Abaco Canyon and the Little Abaco Canyon. Such data covering the entire northern sector of the Bahamas will provide a complete tectono-stratigraphic framework on which to reconstruct the genesis of these canyons and define their role in carbonate transport from the slope to the basin.

\section{CONCLUSIONS}

603 The large dataset covering almost the entire northern Little Bahama Bank slope reveals a wide variety of 604 features attesting to diverse sedimentary processes occurring along the slope and allowing both along-slope 605 and down-slope transport to supply giant canyons on the windward side of this carbonate margin. Off-bank 606 transport including tidal flushing and density cascading promote the export of fine-grained and coarse607 grained materials from the platform. This sedimentary load transits through the numerous canyons incising 608 the middle and lower slope all along the Little Bahama Bank. Prolonging the canyons, distributary furrows 609 are cross-cut by other furrows evidencing the impact of surface currents and bypass processes on this part 610 of the lower slope. Despite the moderate sediment supply feeding the Great Abaco Canyon head, the main 611 supply of this giant canyon appears not to be axial. Many failure scars and slides can be observed in the 612 eastern part of the lower slope. They affect both the contouritic Blake Plateau, the Little Abaco Canyon and 613 the Great Abaco Canyon flanks. The downslope motion induced by slides appears to be the main source of 614 sediment transiting through the canyons. In this way, the two canyons appear to be supplied differently: the 615 Great Abaco Canyon is mainly laterally supplied, and the Little Abaco Canyon is both axially and laterally 616 supplied. These dense sediment flows are sufficient to maintain the morphology of the two giant carbonate canyons. The establishment of these canyons running parallel to the platform was likely related to the Great

618 Abaco Fracture Zone. Energetic bottom currents (Deep Western Boundary Current and Antarctic Bottom 619 Water) seem to prevent the present sediment deposition of a lobe at the mouth of the Little Abaco Canyon and Great Abaco Canyon. The analysis of the backscatter and Very High Resolution seismic data shows a 
621 gradient in deposition on the Little Bahama Bank slope. The eastern part of the slope is more subject to 622 erosion whereas the western part shows more deposition processes. Erosional processes dominate the 623 eastern part of the slope, while the western part is influenced to a greater extent by depositional processes. 624 These spatial discrepancies along with the unusual alignment of the giant canyon with the Little Bahama 625 Bank platform and Great Abaco Fracture Zone suggest that these regions are influenced by a structural 626 control. The structural control takes root in the regional differential subsidence between the eastern versus western sectors of the Great Abaco Fracture Zone and influences sedimentary dynamics on the slope.

\section{ACKNOWLEDGEMENTS}

630 We thank the captain and crew of the $R / V$ Le Suroît, the $R / V$ F.G. Walton Smith and the $R / V$ L'Atalante for 631 the quality of the data acquired during cruise Carambar 1, 1.5 and 2, and Ifremer-Genavir for cruise 632 organization and technical support. We also thank TOTAL for their support. We acknowledge IHS for 633 granting academic Kingdom ${ }^{\circledR}$ software licenses to the University of Bordeaux. Eleanor Georgiadis is 634 thanked for the English corrections. We thank Ángel Puga-Bernabéu, Erwin Adams and the Associate 635 Editor, Jim Hendry for insightful reviews. 


\section{REFERENCES}

Augustin, J.-M and Lurton, X. (2005) Image amplitude calibration and processing for seafloor mapping sonars. Oceans 2005 - Europe, Conference Paper, Article number 1511799, Pages 698-701.

Austin, J., Schlager, W., Palmer, A., Comet, P., Droxler, A., Eberli, G., Fourcade, E., FreemanLynde, R., Fulthorpe, C., Harwood, G., Kuhn, G., Lavoie, D., Leckie, M., Melillo, A., Moore, A., Mullins, H., Ravenne, C., Sager, W., Swart, P., Verbeek, J., Watkins, D. and Williams, C. (1986) Proceedings of the Ocean Drilling Program, Initial Reports Leg. 101.

Babonneau, N., Savoye, B., Cremer, M. and Klein, B. (2002) Morphology and architecture of the present canyon and channel system of the Zaire deep-sea fan. Marine and Petroleum Geology, 19, 445467.

Benson, W.E., Sheridan, R.E., Pastouret, L., Enos, P., Freeman, T., Murdmaa, I.O., Worstell, P., Gradstein, F., Schmidt, R.R., Weaver, F.M. and Stuermer, D.H. (1978) Initial Reports of the Deep Sea Drilling Project, 44. U.S. Government Printing Office.

Bertello, F., Fantoni, R., Franciosi, R., Gatti, V., Ghielmi, M. and Pugliese, A. (2010) From thrust-andfold belt to foreland: hydrocarbon occurrences in Italy. Geological Society, London, Petroleum Geology Conference series, 7, 113-126.

Betzler, C., Lindhorst, S., Eberli, G.P., Lüdmann, T., Möbius, J., Ludwig, J., Schutter, I., Wunsch, M., Reijmer, J.J.G. and Hübscher, C. (2014) Periplatform drift: The combined result of contour current and off-bank transport along carbonate platforms. Geology, 42, 871-874.

Bryden, H.L., Johns, W.E. and Saunders, P.M. (2005) Deep western boundary current east of Abaco: Mean structure and transport. Journal of Marine Research, 63, 35-57.

Buchan, K.C. (2000) The Bahamas. Marine Pollution Bulletin, 41, 94-111.

Busson, J., Joseph, P., Mulder, T., Teles, V., Borgomano, J., Granjeon, D., Betzler, C., Poli, E. and Wunsch, M. (2019) High-resolution stratigraphic forward modeling of a Quaternary carbonate margin: Controls and dynamic of the progradation. Sedimentary Geology, 379, 77-96.

Chabaud, L. (2016) Modèle stratigraphique et processus sédimentaires au Quaternaire sur deux pentes carbonatées des Bahamas (leeward et windward). Université de Bordeaux.

This article is protected by copyright. All rights reserved 
Chabaud, L., Ducassou, E., Tournadour, E., Mulder, T., Reijmer, J.J.G., Conesa, G., Giraudeau, J., Hanquiez, V., Borgomano, J. and Ross, L. (2016) Sedimentary processes determining the modern carbonate periplatform drift of Little Bahama Bank. Marine Geology, 378, 213-229.

Coates, A.G., Collins, L.S., Aubry, M.-P. and Berggren, W.A. (2004) The Geology of the Darien, Panama, and the late Miocene-Pliocene collision of the Panama arc with northwestern South America. Geological Society of America Bulletin, 116, 1327-1344.

Damuth, J.E. (1980) Use of high-frequency $(3.5-12 \mathrm{kHz}$ ) echograms in the study of near-bottom sedimentation processes in the deep-sea: A review. Marine Geology, 38, 51-75.

Damuth, J.E. and Hayes, D.E. (1977) Echo character of the East Brazilian continental margin and its relationship to sedimentary processes. Marine Geology, 24, 73-95.

Duncan, R.A. and Hargraves, R.B. (1984) Plate tectonic evolution of the Caribbean region in the mantle reference frame. Geological Society of America Memoirs, 162, 81-94.

Engebretson, D.C., Cox, A. and Gordon, R.G. (1985) Relative Motions Between Oceanic and Continental Plates in the Pacific Basin. Geological Society of America Special Papers, 206, 1-60.

Enos, P. (1974) Surface sediment facies of the Florida-Bahamas Plateau. Geological Society of America Map. Geological Society of America.

Fauquembergue, K. (2018) Transferts sédimentaires sur une marge carbonatémoderne de la plate-forme à la plaine abyssale : marge nord de Little Bahama Bank, Bahamas. Université de Bordeaux.

Fauquembergue, K., Ducassou, E., Mulder, T., Hanquiez, V., Perello, M.-C., Poli, E. and Borgomano, J. (2018) Genesis and growth of a carbonate Holocene wedge on the northern Little Bahama Bank. Marine and Petroleum Geology, 96, 602-614.

Guiastrennec-Faugas, L., Gillet, H., Jacinto, R.S., Dennielou, B., Hanquiez, V., Schmidt, S., Simplet, L. and Rousset, A. (2020) Upstream migrating knickpoints and related sedimentary processes in a submarine canyon from a rare 20-year morphobathymetric time-lapse (Capbreton submarine canyon, Bay of Biscay, France). Marine Geology, 106143.

Hanquiez, V., Mulder, T., Lecroart, P., Gonthier, E., Marchès, E. and Voisset, M. (2007) High resolution seafloor images in the Gulf of Cadiz, Iberian margin. Marine Geology, 246, 42-59.

This article is protected by copyright. All rights reserved 
Hanquiez, V., Mulder, T., Toucanne, S., Lecroart, P., Bonnel, C., Marchès, E. and Gonthier, E. (2010) The sandy channel-lobe depositional systems in the Gulf of Cadiz: Gravity processes forced by contour current processes. Sedimentary Geology, 229, 110-123.

Hardy, J.W. and Henderson, K.G. (2003) Cold Front Variability in the Southern United States and the Influence of Atmospheric Teleconnection Patterns. Physical Geography, 24, 120-137.

Hine, A.C. and Neumann, A.C. (1977) Shallow Carbonate-Bank-Margin Growth and Structure, Little Bahama Bank, Bahamas. AAPG Bulletin, 61, 376-406.

Hine, A.C., Wilber, R.J., Bane, J.M., Neumann, A.C. and Lorenson, K.R. (1981) Offbank transport of carbonate sands along open, leeward bank margins: Northern Bahamas. Marine Geology, 42, 327348.

Hollister, C.D., Flood, R.D., Johnson, D.A., Lonsdale, P. and Southard, J.B. (1974) Abyssal Furrows and Hyperbolic Echo Traces on the Bahama Outer Ridge. Geology, 2, 395-400.

Hollister, C.D. and Heezen, B.C. (1972) Geologic effects of ocean bottom currents: Western North Atlantic. Woods Hole Oceanographic Institution.

James, K.H. (2009) Evolution of Middle America and the in situ Caribbean Plate model. Geological Society, London, Special Publications, 328, 127-138.

Johns, W.E., Kanzow, T. and Zantopp, R. (2005) Estimating ocean transports with dynamic height moorings: An application in the Atlantic Deep Western Boundary Current at $26^{\circ}$ N. Deep Sea Research Part I: Oceanographic Research Papers, 52, 1542-1567.

Komar, P.D. (1971) Hydraulic Jumps in Turbidity Currents. GSA Bulletin, 82, 1477-1488.

Lee, T.N., Johns, W.E., Zantopp, R.J. and Fillenbaum, E.R. (1996) Moored Observations of Western Boundary Current Variability and Thermohaline Circulation at $26.5^{\circ}$ in the Subtropical North Atlantic. J. Phys. Oceanogr., 26, 962-983.

Meinen, C.S., Garzoli, S.L., Johns, W.E. and Baringer, M.O. (2004) Transport variability of the Deep Western Boundary Current and the Antilles Current off Abaco Island, Bahamas. Deep Sea Research Part I: Oceanographic Research Papers, 51, 1397-1415.

This article is protected by copyright. All rights reserved 
Meschede, M. and Frisch, W. (1998) A plate-tectonic model for the Mesozoic and Early Cenozoic history of the Caribbean plate. Tectonophysics, 296, 269-291.

Mulder, T., Ducassou, E., Eberli, G.P., Hanquiez, V., Gonthier, E., Kindler, P., Principaud, M., Fournier, F., Leonide, P., Billeaud, I., Marsset, B., Reijmer, J.J.G., Bondu, C., Joussiaume, R. and Pakiades, M. (2012a) New insights into the morphology and sedimentary processes along the western slope of Great Bahama Bank. Geology, 40, 603-606.

Mulder, T., Ducassou, E., Gillet, H., Hanquiez, V., Tournadour, E., Combes, J., Eberli, G.P., Kindler, P., Gonthier, E., Conesa, G., Robin, C., Sianipar, R., Reijmer, J.J.G. and François, A. (2012b) Canyon morphology on a modern carbonate slope of the Bahamas: Evidence of regional tectonic tilting. Geology, 771-774.

Mulder, T., Ducassou, E., Gillet, H., Hanquiez, V., Principaud, M., Chabaud, L., Eberli, G.P., Kindler, P., Billeaud, I., Gonthier, E., Fournier, F., Léonide, P. and Borgomano, J. (2014) First discover of channel-levee complexes in a modern deep-water carbonate slope environment. Journal of Sedimentary Reserarch, V.84, 1139 to 1146.

Mulder, T., Joumes, M., Hanquiez, V., Gillet, H., Reijmer, J.J.G., Tournadour, E., Chabaud, L., Principaud, M., Schnyder, J.S.D., Borgomano, J., Fauquembergue, K., Ducassou, E. and Busson, J. (2017) Carbonate slope morphology revealing sediment transfer from bank-to-slope (Little Bahama Bank, Bahamas). Marine and Petroleum Geology, 83, 26-34.

Mulder, T., Gillet, H., Hanquiez, V., Ducassou, E., Fauquembergue, K., Principaud, M., Conesa, G., Goff, J.L., Ragusa, J., Bashah, S., Bujan, S., Reijmer, J.J.G., Cavailhes, T., Droxler, A.W., Blank, D.G., Guiastrennec, L., Fabregas, N., Recouvreur, A. and Seibert, C. (2018) Carbonate slope morphology revealing a giant submarine canyon (Little Bahama Bank, Bahamas). Geology, 46, 31-34.

Mullins, H.T., Heath, K.C., Van Buren, H.M. and Newton, C.R. (1984) Anatomy of a modern openocean carbonate slope: northern Little Bahama Bank. Sedimentology, 31, 141-168.

Mullins, H.T., Keller, G.H., Kofoed, J.W., Lambert, D.N., Stubblefield, W.L. and Warme, J.E. (1982) Geology of Great Abaco Submarine Canyon (Blake Plateau): Observations from the research submersible “Alvin”. Marine Geology, 48, 239-257.

This article is protected by copyright. All rights reserved 
Mullins, H.T. and Neumann, A.C. (1979) Deep Carbonate Bank Margin Structure and Sedimentation in the Northern Bahamas. Soc. Econ. Paleontologists Mineralogists Spec. Pub, 165-192.

Mullins, H.T., Neumann, A.C., Wilber, R.J., Hine, A.C. and Chinburg (5), S.J. (1980) Carbonate Sediment Drifts in Northern Straits of Florida. AAPG Bulletin, 64, 1701-1717.

Neumann, G. and Pierson, W.J.J. (1966) Principles of physical oceanography. Englewood Cliffs, NJ (USA) Prentice Hall.

Paull, C., Caress, D., Lundsten, E., Gwiazda, R., Anderson, K., McGann, M., Conrad, J., Edwards, B. and Sumner, E. (2013) Anatomy of the La Jolla submarine canyon system; offshore Southern California. Marine Geology, 335, 16-34.

Pindell, J.L. (1994) Evolution of the Gulf of Mexico and the Caribbean. Caribbean geology: an introduction, 13-39.

Principaud, M., Mulder, T., Hanquiez, V., Ducassou, E., Eberli, G.P., Chabaud, L. and Borgomano, J. (2018) Recent morphology and sedimentary processes along the western slope of Great Bahama Bank (Bahamas). Sedimentology, 65, 2088-2116.

Puga-Bernabéu, Á., Webster, J.M., Beaman, R.J. and Guilbaud, V. (2011) Morphology and controls on the evolution of a mixed carbonate-siliciclastic submarine canyon system, Great Barrier Reef margin, north-eastern Australia. Marine Geology, 289, 100-116.

Rankey, E.C. and Doolittle, D.F. (2012) Geomorphology of carbonate platform-marginal uppermost slopes: Insights from a Holocene analogue, Little Bahama Bank, Bahamas. Sedimentology, 59, $2146-2171$.

Reeder, S.L. and Rankey, E.C. (2009) Controls on morphology and sedimentology of carbonate tidal deltas, Abacos, Bahamas. Marine Geology, 267, 141-155.

Reijmer, J.J.G., Palmieri, P. and Groen, R. (2012) Compositional variations in calciturbidites and calcidebrites in response to sea-level fluctuations (Exuma Sound, Bahamas). Facies, 58, 493-507.

Richardson, P.L. (1977) On the crossover between the Gulf Stream and the Western Boundary Undercurrent. Deep Sea Research, 24, 139-159.

This article is protected by copyright. All rights reserved 
Ross, M.I. and Scotese, C.R. (1988) A hierarchical tectonic model of the Gulf of Mexico and Caribbean region. Tectonophysics, 155, 139-168.

Schlager, W. (2005) Carbonate Sedimentology and Sequence Stratigraphy. SEPM Soc for Sed Geology, $210 \mathrm{pp}$.

Shepard and Dill (1966) Submarine canons and Other Sea Valleys. Rand Mc.ally \& Company.

Sheridan, R., Mullins, H., Austin Jr, J., Ball, M., Ladd, J. and Grow, J. (1988a) Geology and geophysics of the Bahamas. The Geology of North America, 1, 2.

Sheridan, R.E., Mullins, H.T., Austin Jr, J.A., Ball, M.M., Ladd, J.W. and Grow, J.A. (1988b) Geology and geophysics of the Bahamas. The Geology of North America, 1, 2.

Sheridan, R.E. and Osburn, W.L. (1975) Marine Geological and Geophysical Studies of the Florida Blake Plateau - Bahamas Area. 9-32.

Tournadour, E. (2015) Architecture et dynamique sédimentaire d'une pente carbonatée moderne: exemple de la pente nord de Little Bahama Bank (LBB), Bahamas. Université de Bordeaux.

Tournadour, E., Mulder, T., Borgomano, J., Hanquiez, V., Ducassou, E. and Gillet, H. (2015) Origin and architecture of a Mass Transport Complex on the northwest slope of Little Bahama Bank (Bahamas): Relations between off-bank transport, bottom current sedimentation and submarine landslides. Sedimentary Geology, 317, 9-26.

Tournadour, E., Mulder, T., Borgomano, J., Gillet, H., Chabaud, L., Ducassou, E., Hanquiez, V. and Etienne, S. (2017) Submarine canyon morphologies and evolution in modern carbonate settings: The northern slope of Little Bahama Bank, Bahamas. Marine Geology, 391, 76-97.

Tubau, X., Paull, C.K., Lastras, G., Caress, D.W., Canals, M., Lundsten, E., Anderson, K., Gwiazda, R. and Amblas, D. (2015) Submarine canyons of Santa Monica Bay, Southern California: Variability in morphology and sedimentary processes. Marine Geology, 365, 61-79.

Wilson, P.A. and Roberts, H.H. (1992) Carbonate-periplatform sedimentation by density flows: A mechanism for rapid off-bank and vertical transport of shallow-water fines. Geology, 20, 713.

Wilson, P.A. and Roberts, H.H. (1995) Density cascading: Off-shelf sediment transport, evidence and implications, Bahama Banks. Journal of Sedimentary Research, 45-56.

This article is protected by copyright. All rights reserved 


\section{FIGURE CAPTIONS}

Fig. 1. Geographical context of the study including Carambar 1 Leg 2, Carambar 1.5 and Carambar 2 Leg 1 survey location. GAC $=$ Great Abaco Canyon; $\mathrm{LAC}=$ Little Abaco Canyon; GAFZ $=$ Great Abaco Fracture Zone (thin grey line); DWBC = Deep Western Boundary Current; AABW = Antarctic Bottom Water.

Fig. 2. (A) Overview of Little Bahama Bank (LBB) slope morphology evidenced by bathymetric data. Black squares show the locations of subsequent figures and tables. Location of the different slope domain limits is also shown. (B) Three-dimensional east-west view of the study area. White lines: location of different slope domain limits. Black and blue dashed lines = location of profiles in (C). Vertical exaggeration x3. (C) Little Bahama Bank slope profiles with respective slope domains. GAC = Great Abaco Canyon; LAC = Little Abaco Canyon; MWD = mass wasting deposits; $\mathrm{sw}=$ sediment waves; $\mathrm{s}=$ slides; MTC $=$ mass transport complex.

Fig. 3. (A) Close-up of the bathymetry of the slope canyons with an up dip linear part (see location on Fig.

2). Canyon flanks represented in black lines. (B) High resolution bathymetry of the mounds and pockmarks with associated profiles.

Fig. 4. Distinctive morphological features of the Little Bahama Bank (LBB) lower slope (see location on Fig. 2). (A) Close up of cross-cutting furrows F1 and F2 affecting the lower slope. (B) Close-up of the sediment waves (SW; dotted black line; graphic representing depth profile) over the lobe (dotted red line) at an eastern slope canyon mouth. (C) Close-up of the slides (S) affecting the Great Abaco Canyon flanks. (D) Close-up of the Little Abaco Canyon mouth showing the location of the sediment lobe (LAC Lobe).

Fig. 5. (A) Close-up of the Great Abaco Canyon and the Little Abaco Canyon and depth profile locations (see location on Fig. 2). (B) North-south profiles of the Great Abaco Canyon and the Little Abaco Canyon displaying U shaped canyons. (C) Little Abaco Canyon longitudinal depth profile. (D) Great Abaco Canyon longitudinal depth profile. $\mathrm{PP}=$ plunge pool; $\mathrm{kn}=$ knickpoint .

Fig. 6. High resolution bathymetry of the distal part of the canyons showing the plunge pools (white dashed lines) of the Great Abaco Canyon (A) and Little Abaco Canyon (B).

Fig. 7. Backscatter map of the northern Little Bahama Bank (LBB) slope. White boxes represent the location of the acoustic facies and echofacies summarized in Table 1.

Fig. 8. Acoustic facies distribution on the northern Little Bahama Bank (LBB) slope.

Fig. 9. Echofacies distribution on the northern Little Bahama Bank (LBB) slope. 
Fig. 10. Synthetic map of the northern Little Bahama Bank (LBB) slope sedimentary processes (C) obtained by the integration of acoustic facies (A) and echofacies (B) distributions.

Fig. 11. Synthetic map of the Little Bahama Bank (LBB) slope sedimentary processes. Cold colours (first column) represent processes and geometries mainly generated by deposition. Warm colours (second column) represent processes and geometries mainly influenced by erosion. The third column represents platform facies [from Enos (1974) and modified by Tournadour (2015)].

Fig. 12. Three-dimensional views (vertical exaggeration $\mathrm{x}$ ) ) of (A) the Little Bahama Bank (LBB) slope environments and $(\mathbf{B})$ of the conceptual model of the sedimentary processes on the northern LBB slope; platform facies from Enos (1974) and modified by Tournadour (2015). GAC = Great Abaco Canyon; LAC $=$ Little Abaco Canyon; DWBC $=$ Deep Western Boundary Current.

Fig. 13. High resolution bathymetry of (A) the Great Abaco Canyon head and (B) of the eastern canyons. $\mathrm{GAC}=$ Great Abaco Canyon .

Table 1. Sedimentary facies interpretations using both acoustic facies, echofacies and bathymetry. Location of the acoustic facies on Fig. 7. The Very High Resolution (VHR) facies are located at the same place as the reflectivity data.

Table 2. Classification and description of acoustic facies.

Table 3. Classification and description of echofacies. 


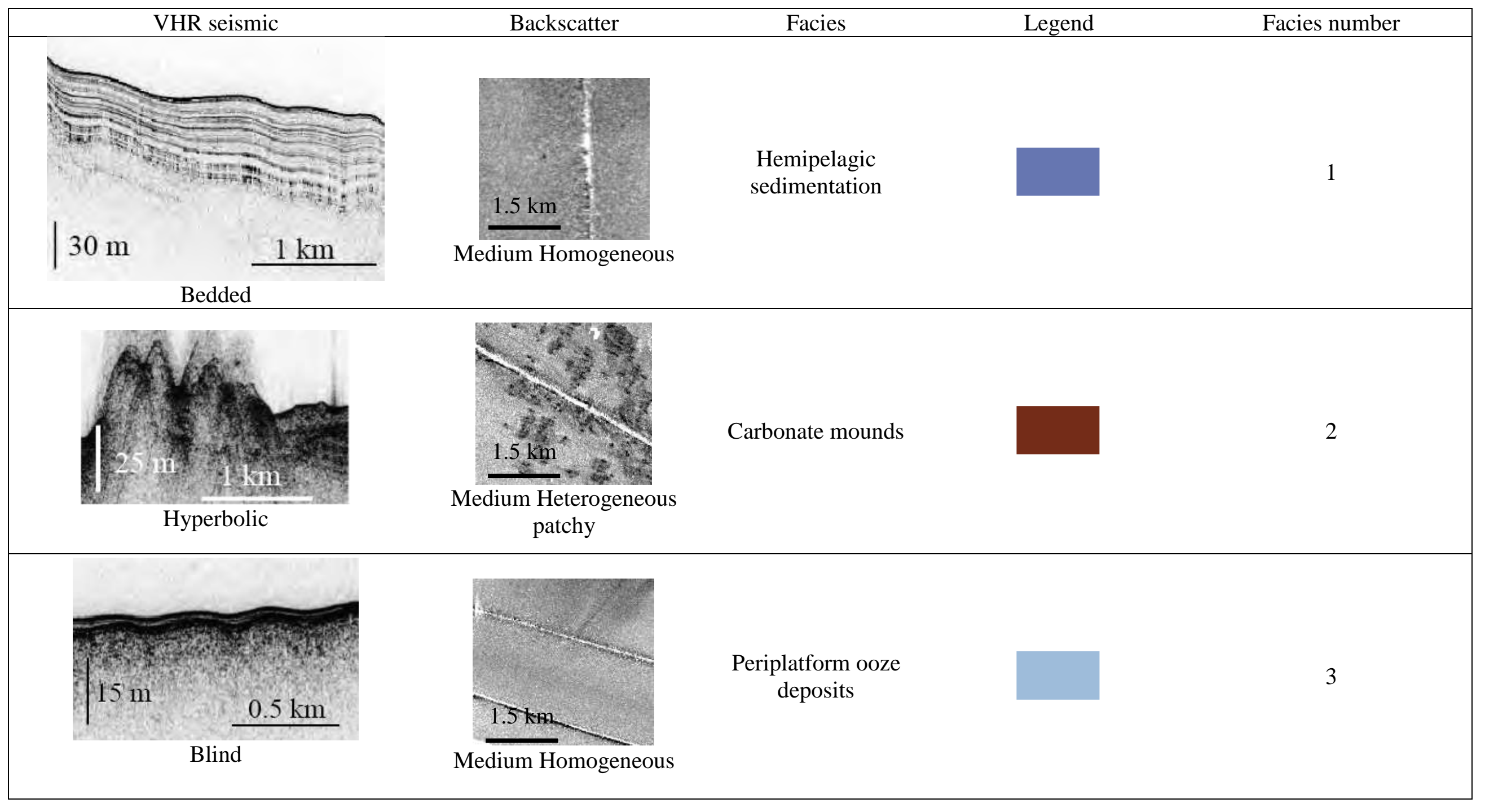




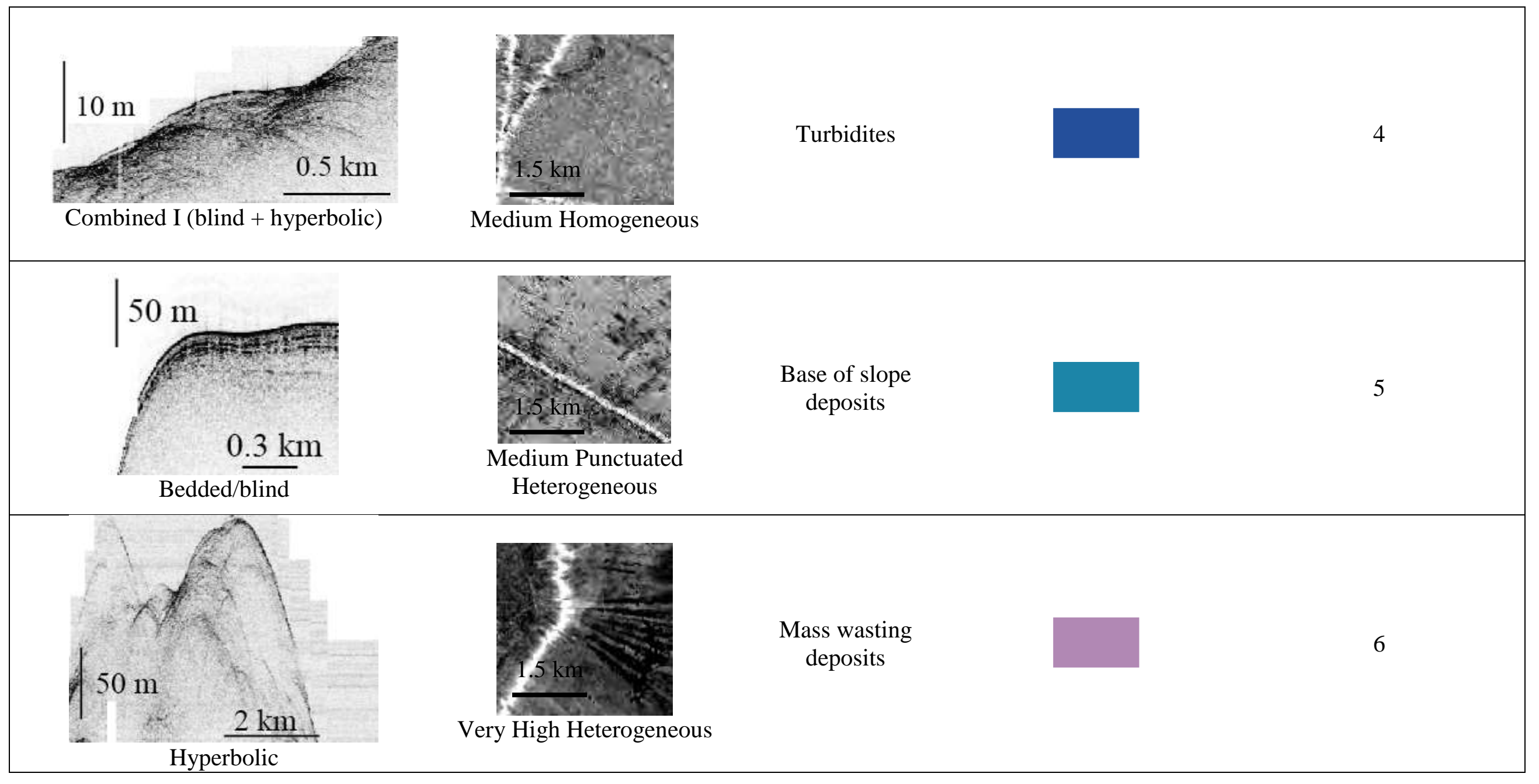




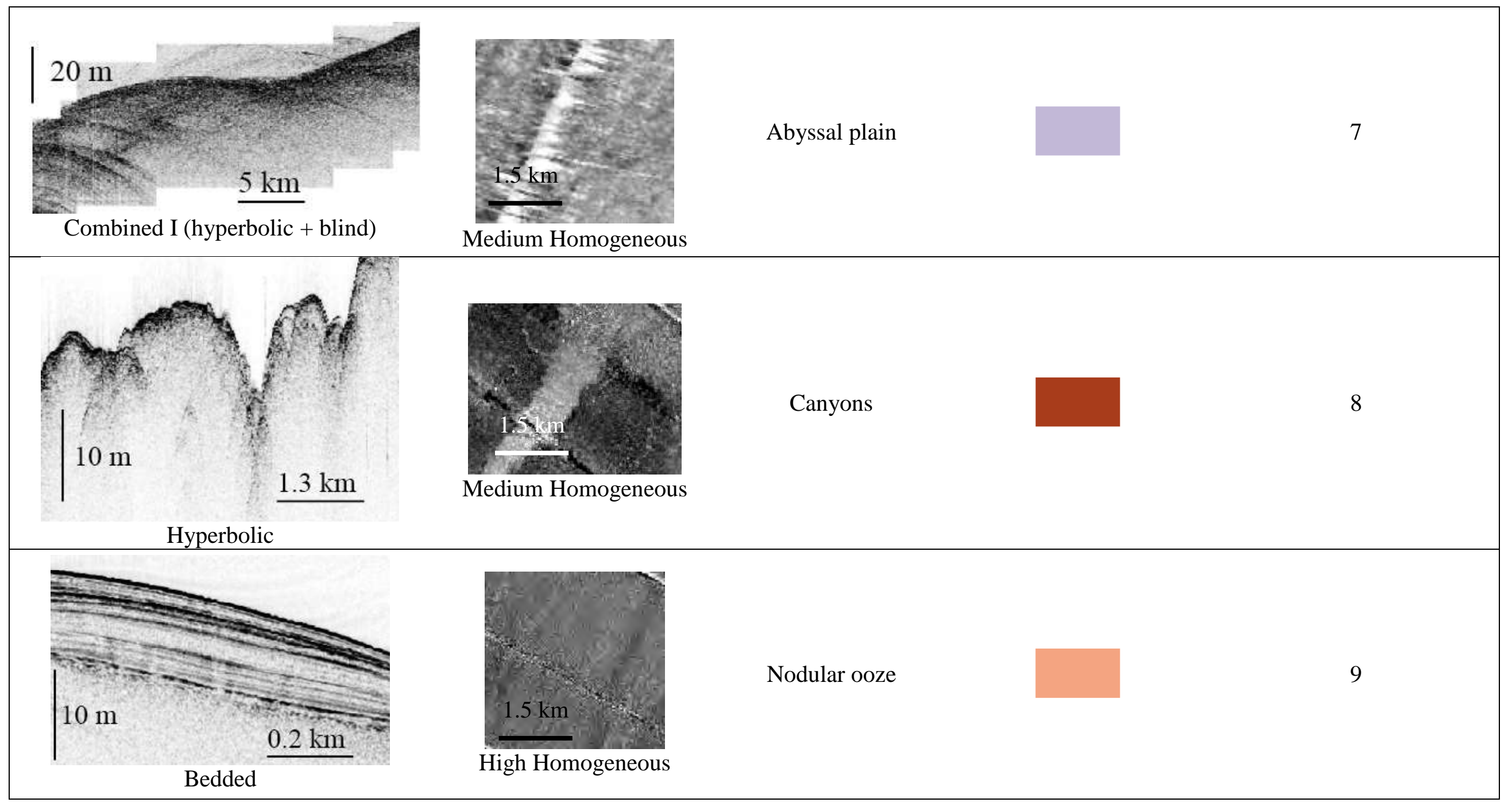




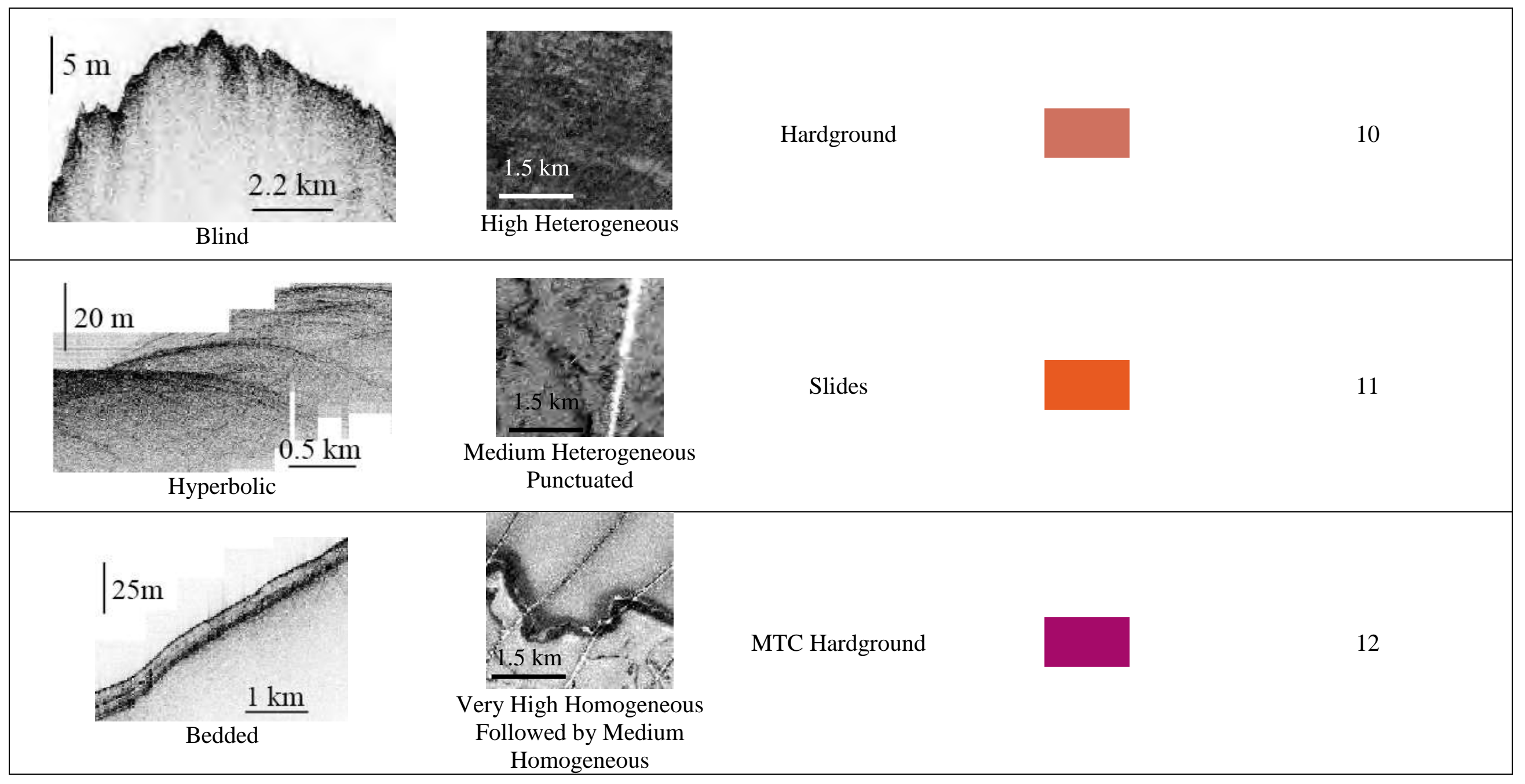




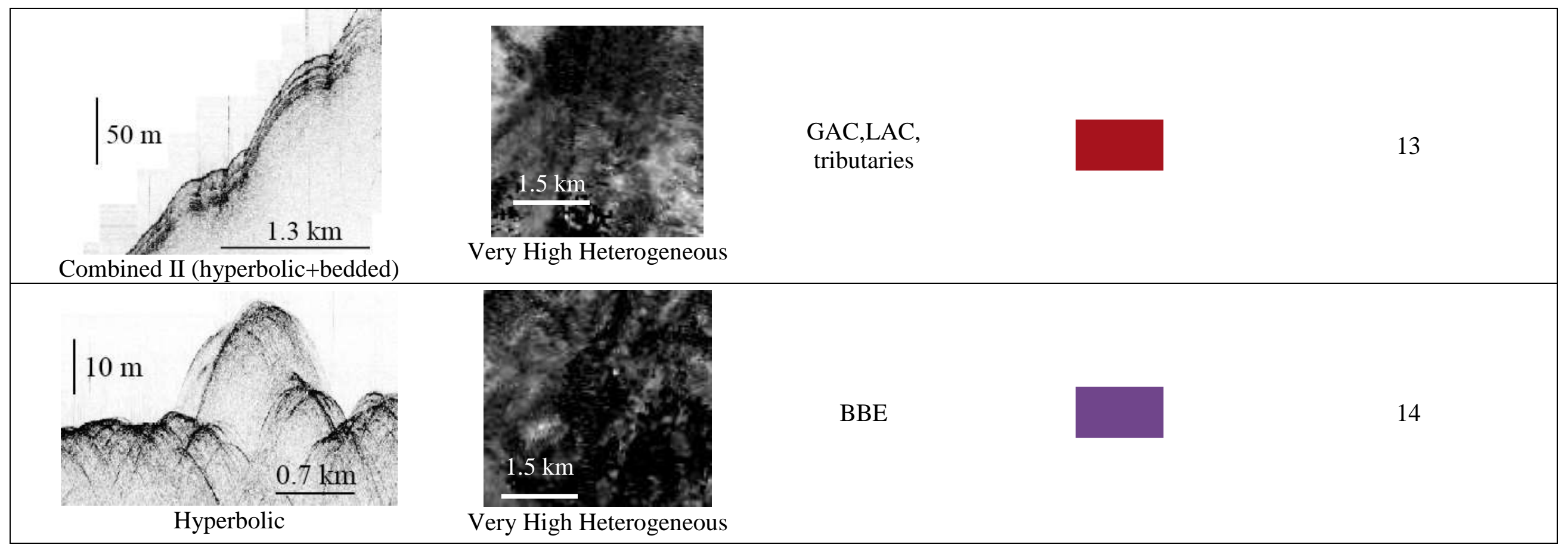




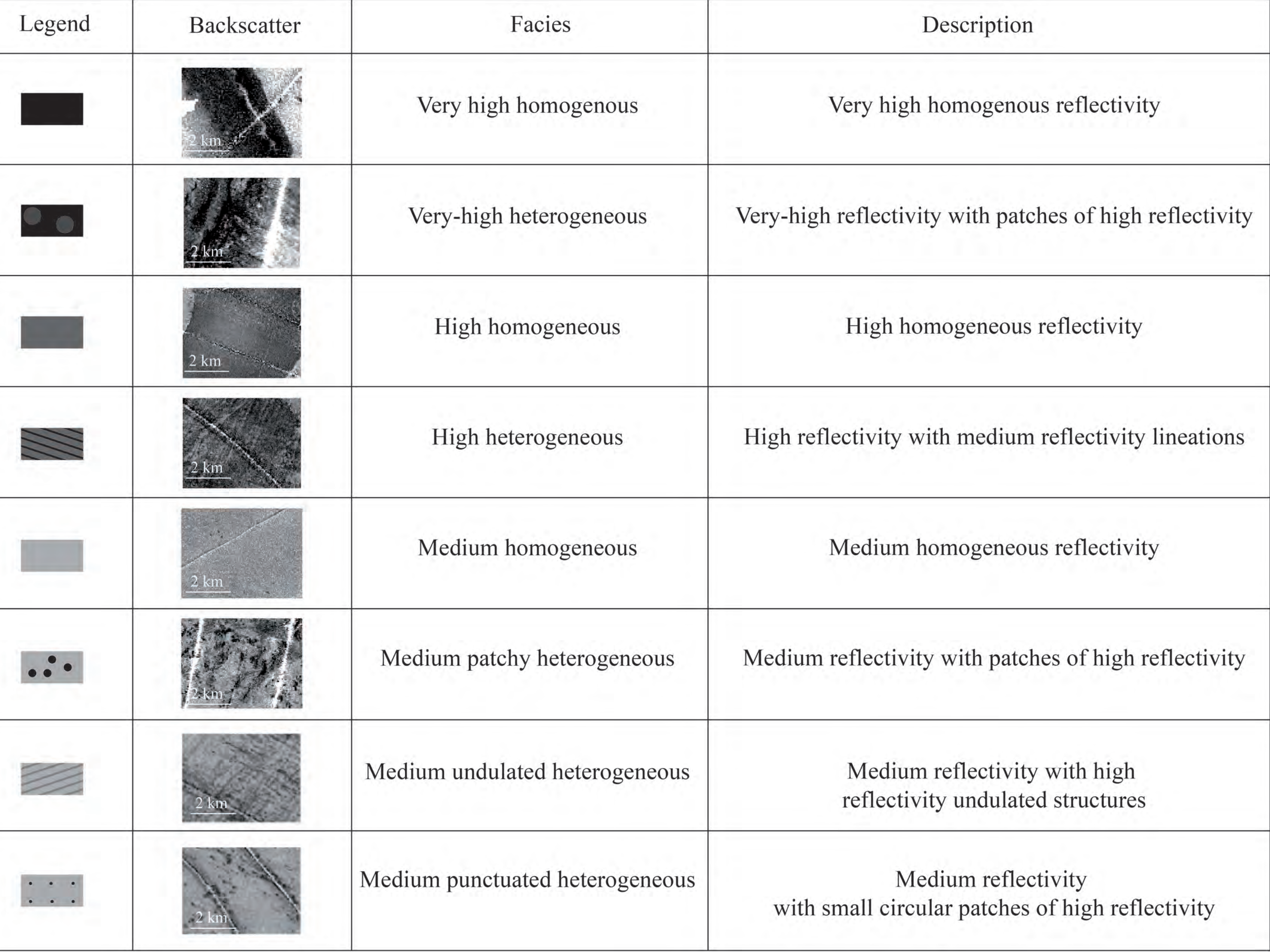




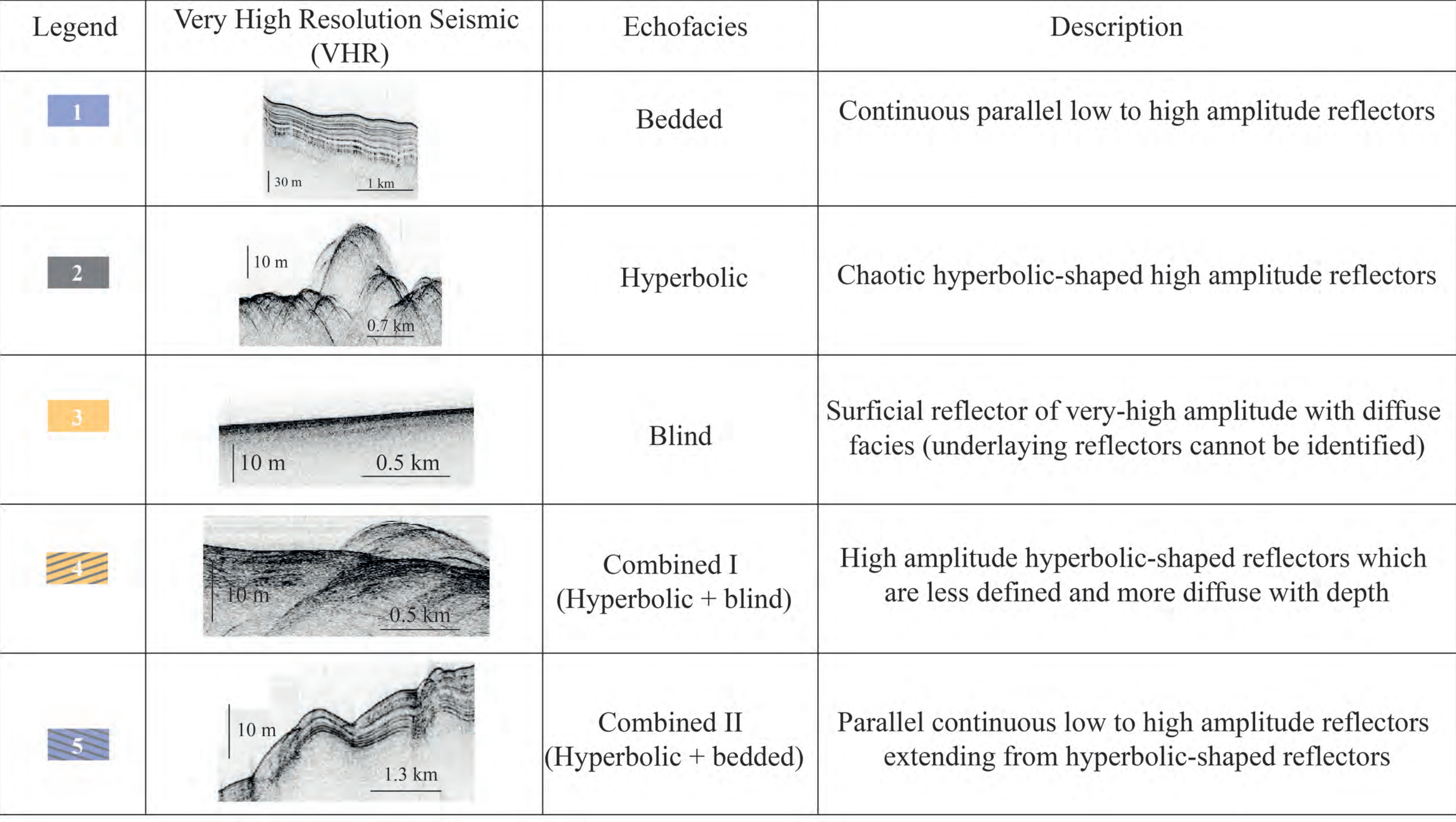




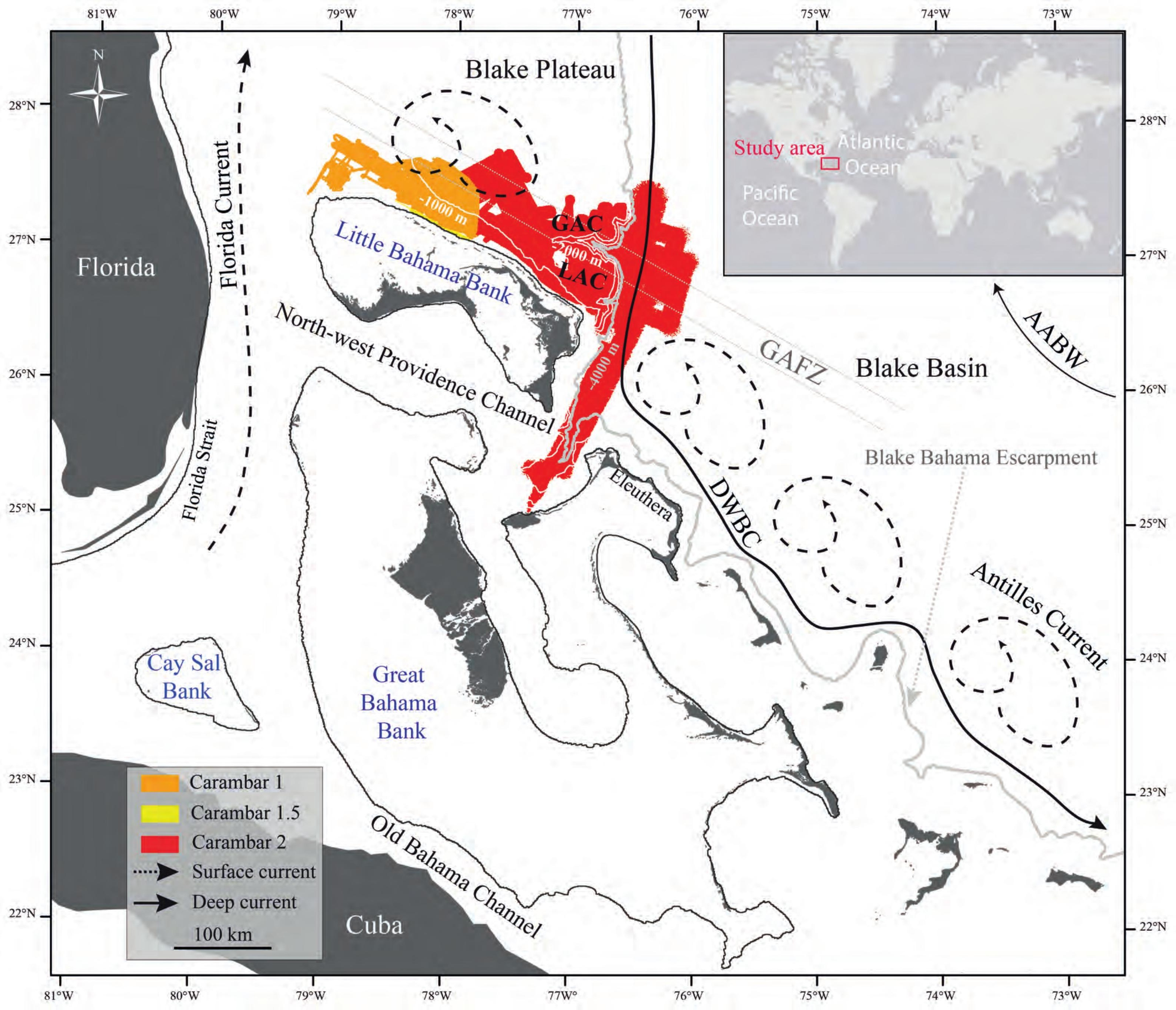




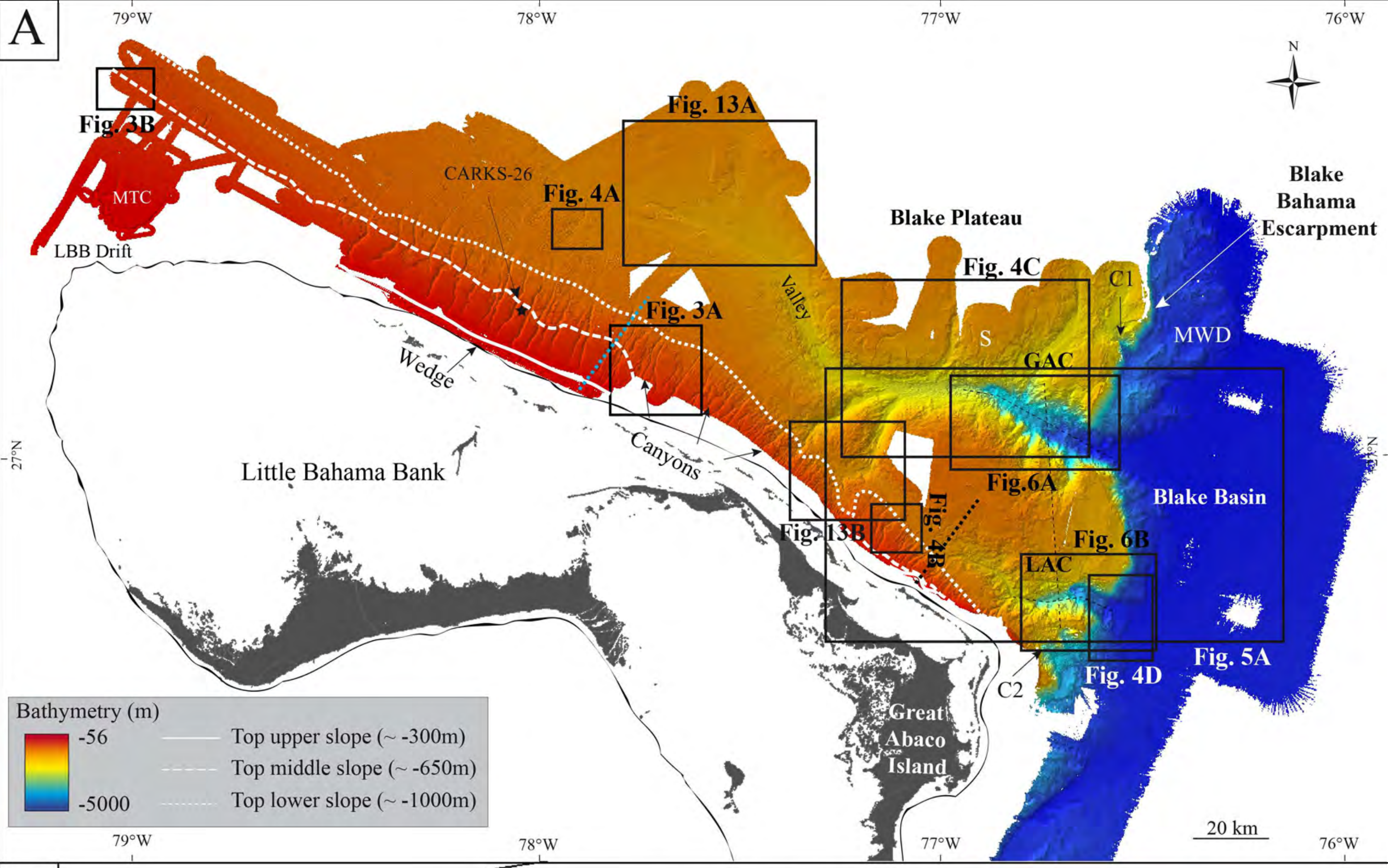

\section{B}

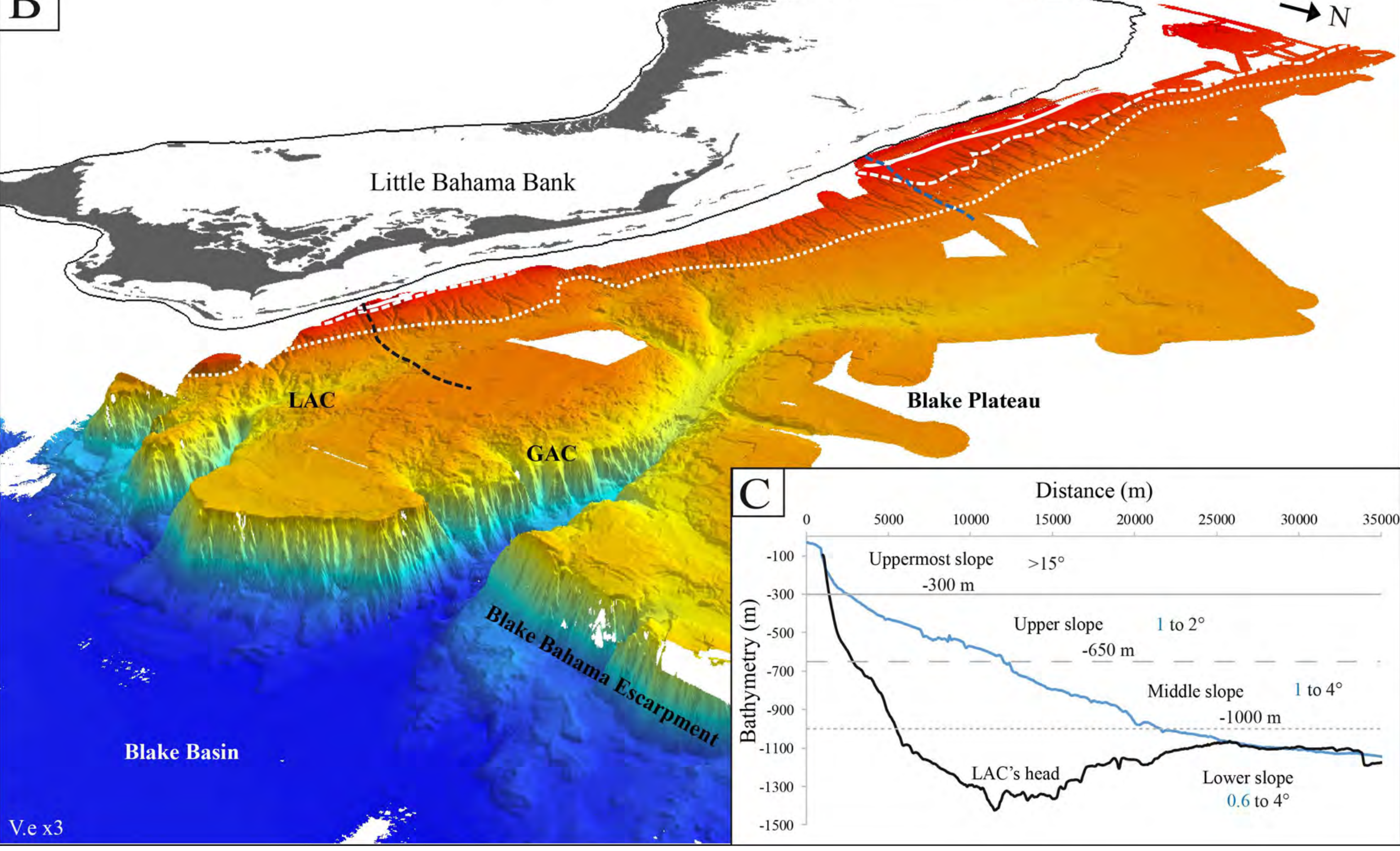




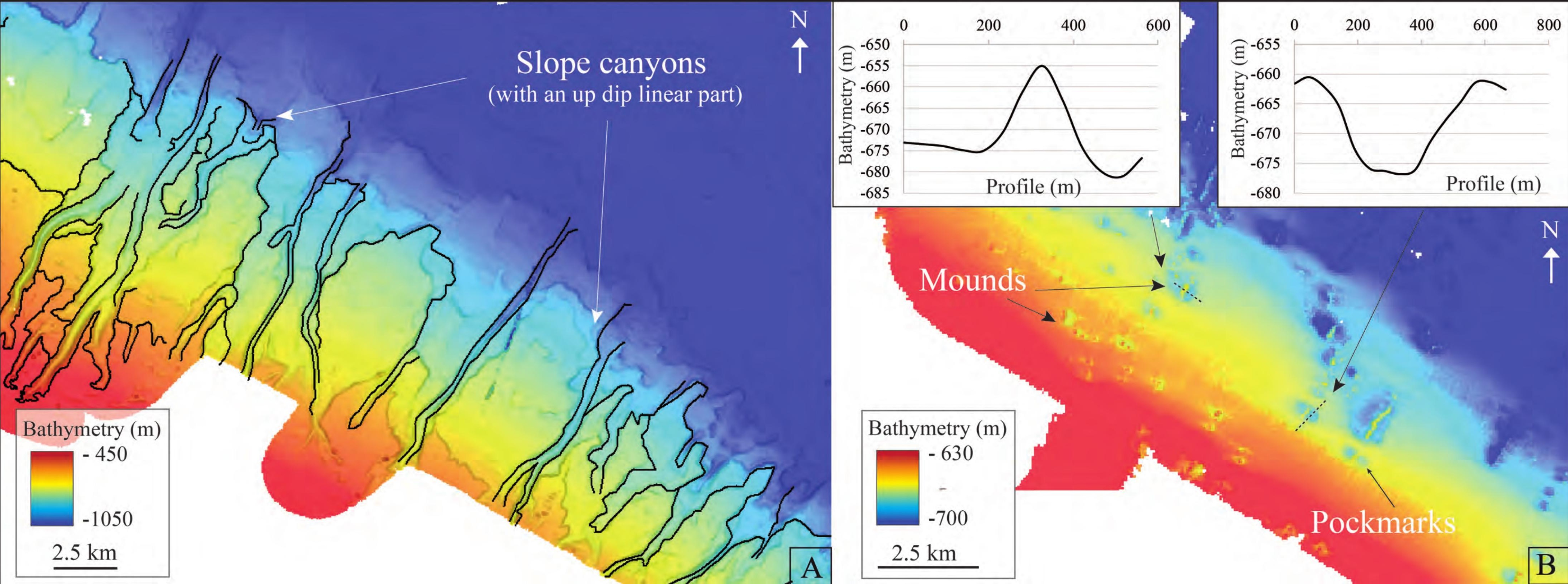




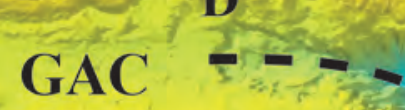

\section{Relict Plateau}

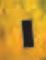

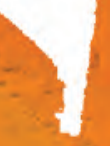
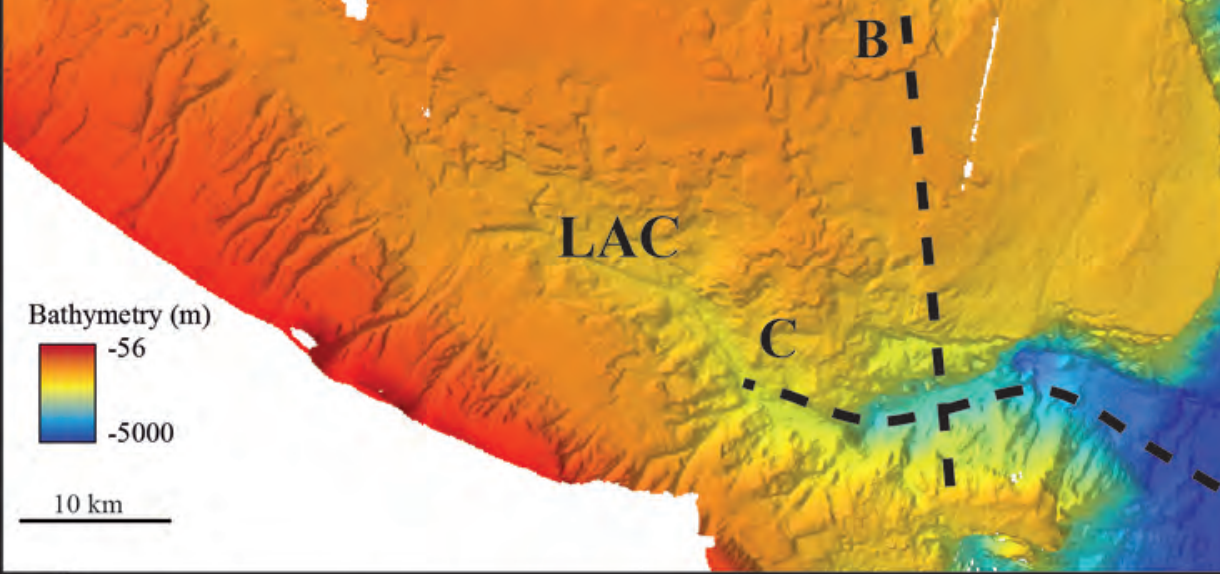

B

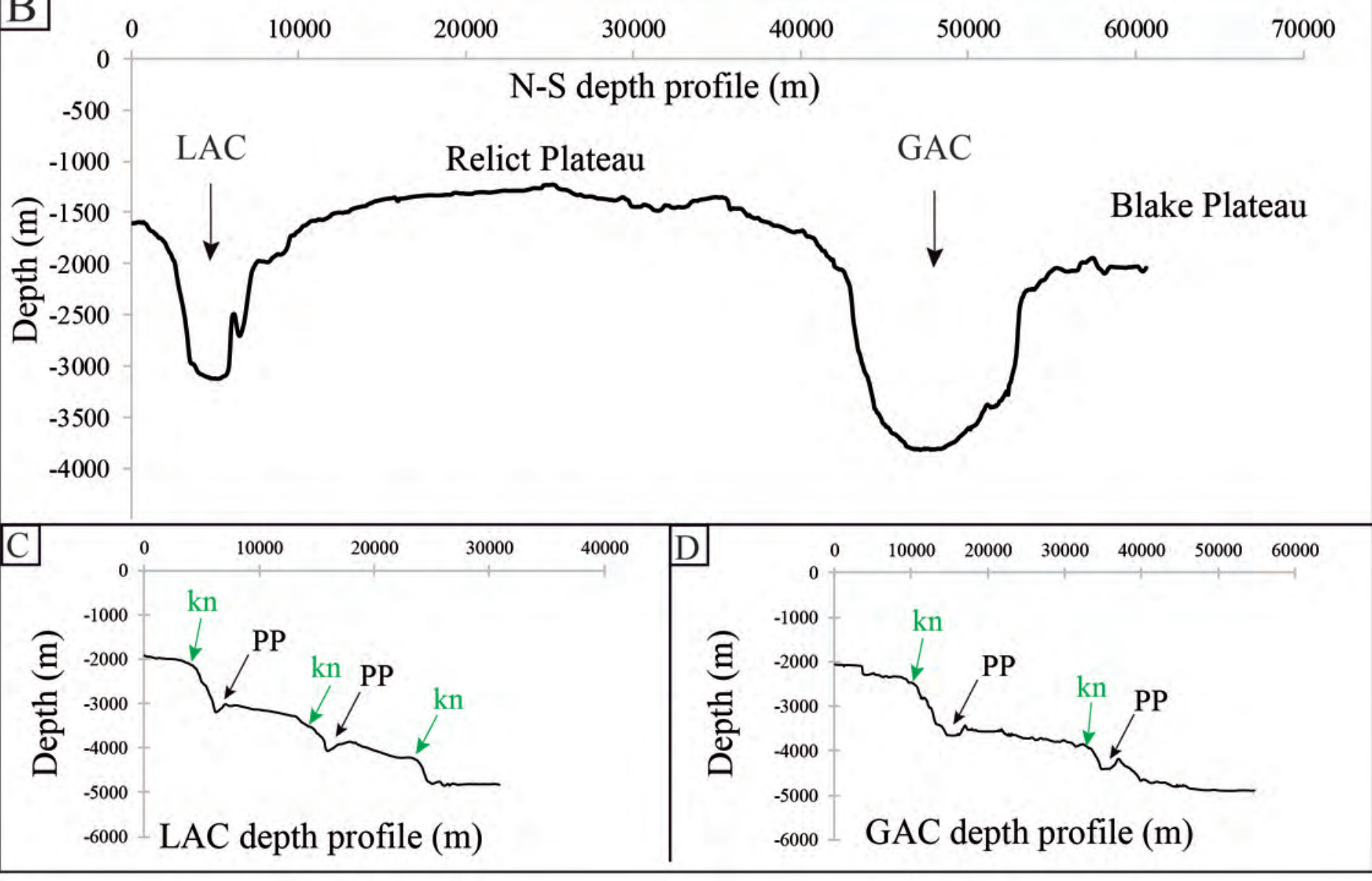

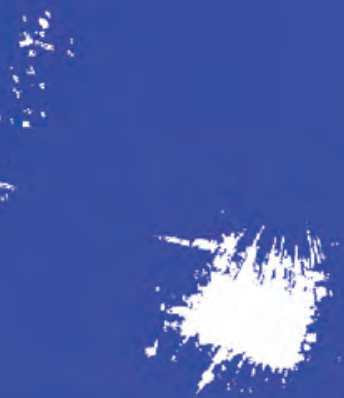

\section{Blake Basin}

Blake Plateau 


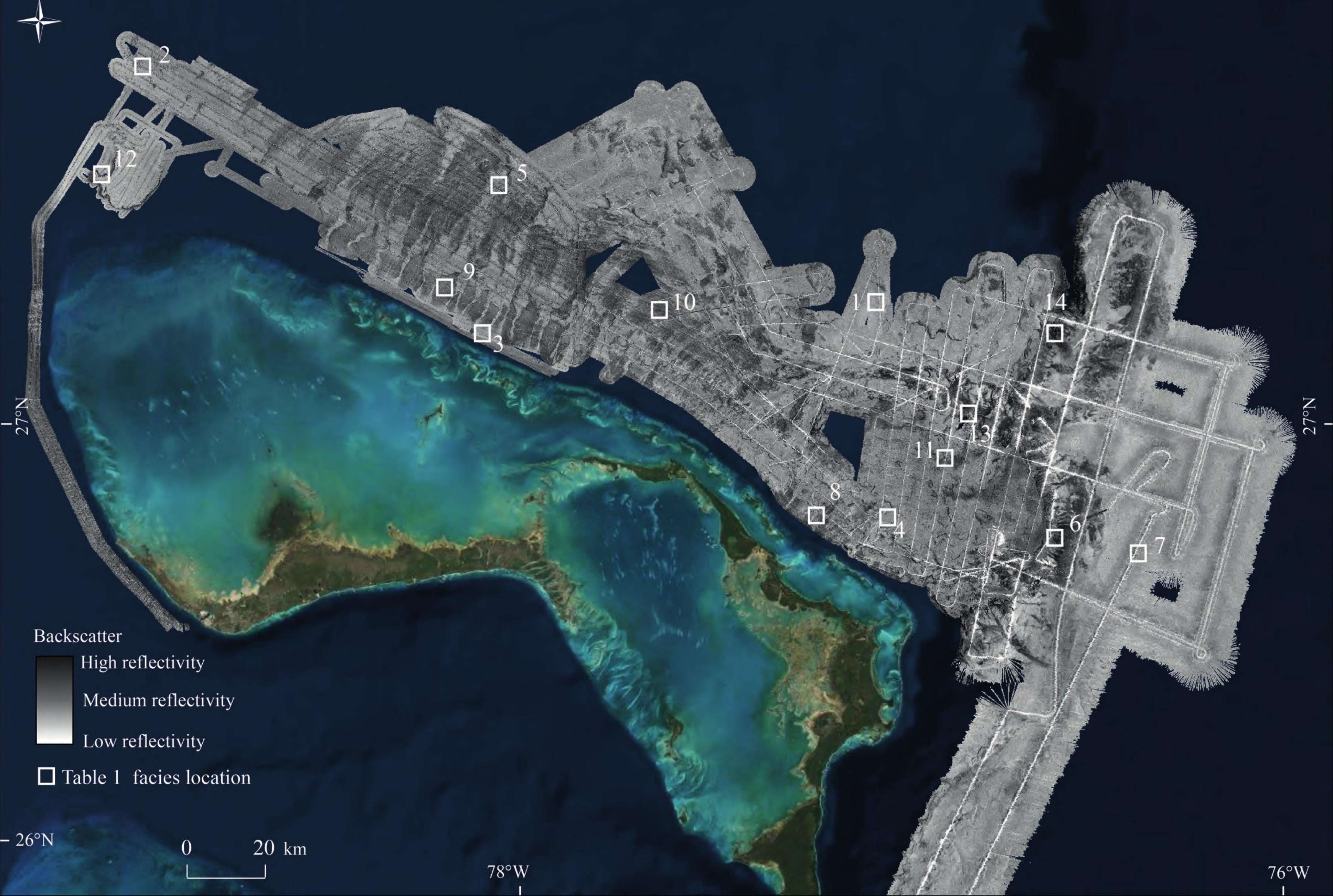




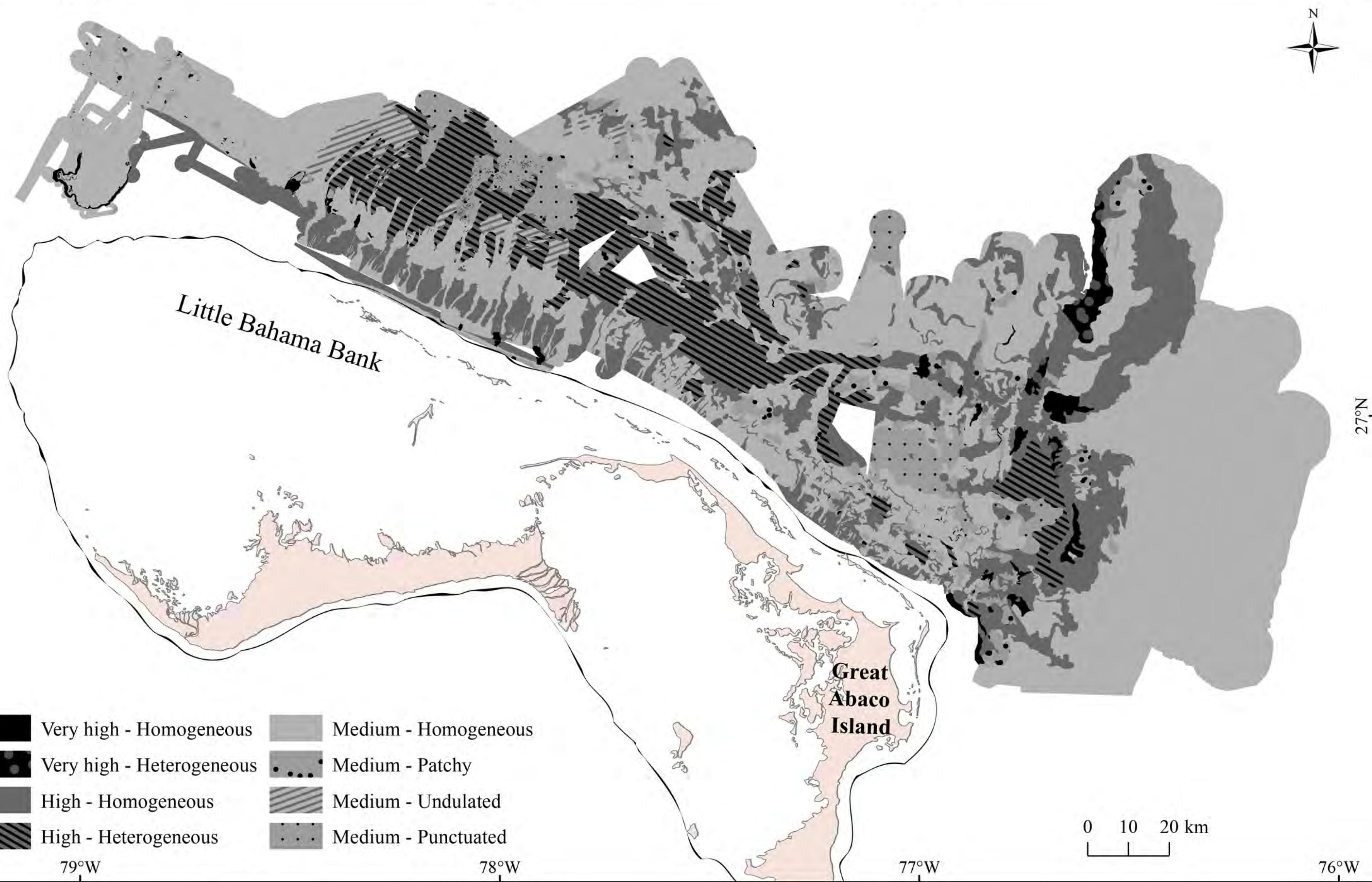



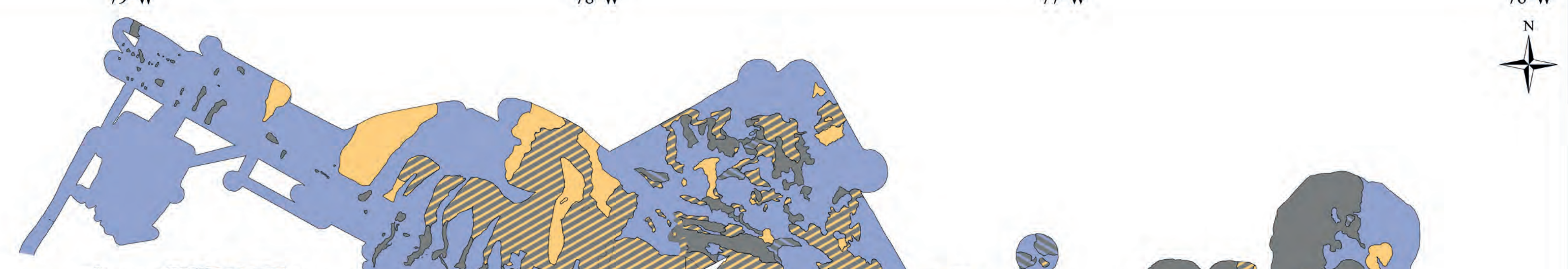

1 Bedded

2 Hyperbolic

Blind

Combine I (hyperbolic + blind)

Combine II (hyperbolic + bedded)

$+1$

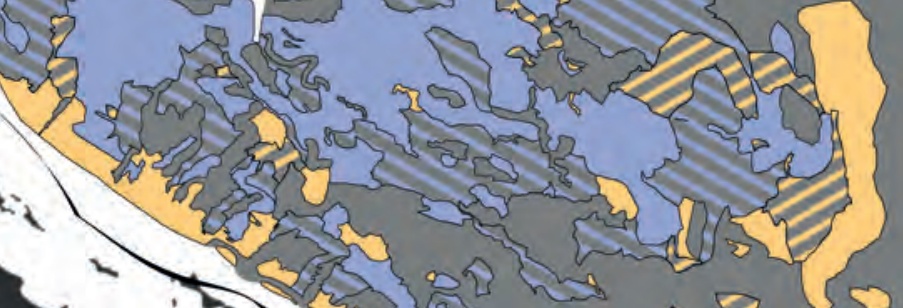

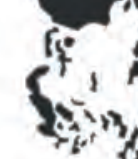

S

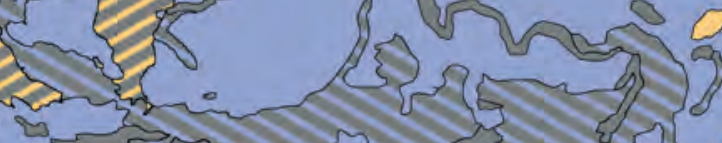

(2)

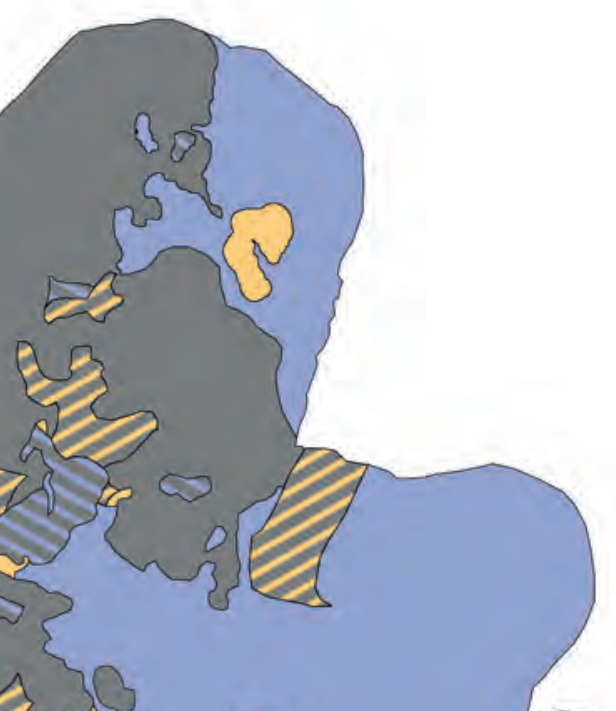

$\sum_{\substack{z \\ \vdots}}^{3}$ 

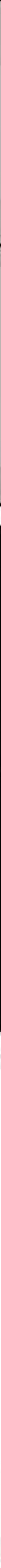

Deposition

11 Henipelagic sedimentation

2 Carbonate mound deposits

15 Periplatform oose deposits

4 Turtidites

BIIIse of slope deposits

116. Mass wasting deposits

NDIT Abyssal Plain
Erosion

8. Canyons

댄. Nodular nose

10 Harderound

III sliding zone

12 Harderound MTC

13. $\mathrm{GAC}+\mathrm{LAC}+$ Tributaries

14 Blake Bahama Escapnes
$L^{6}$

W 


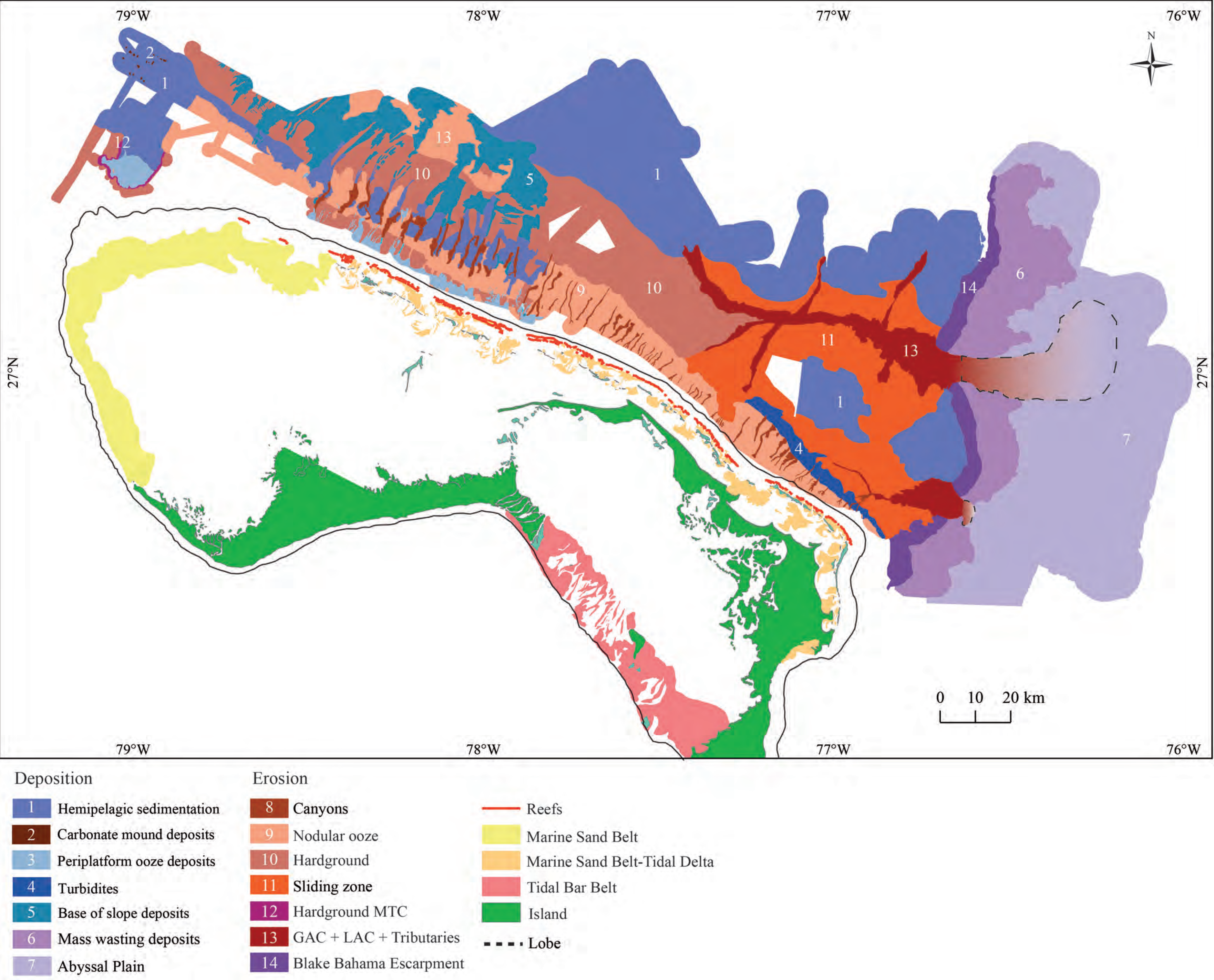


Marine Sand Belt - Tidal Delta

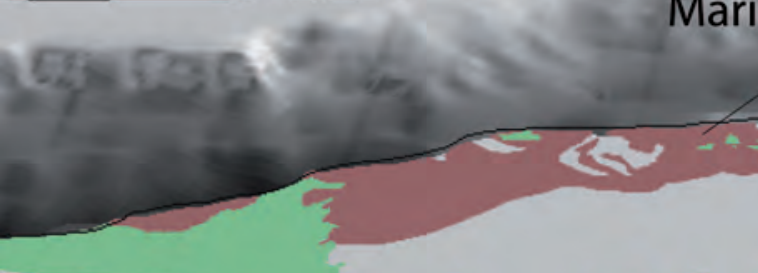

Little Bahama Bank

Marine Sand Belt

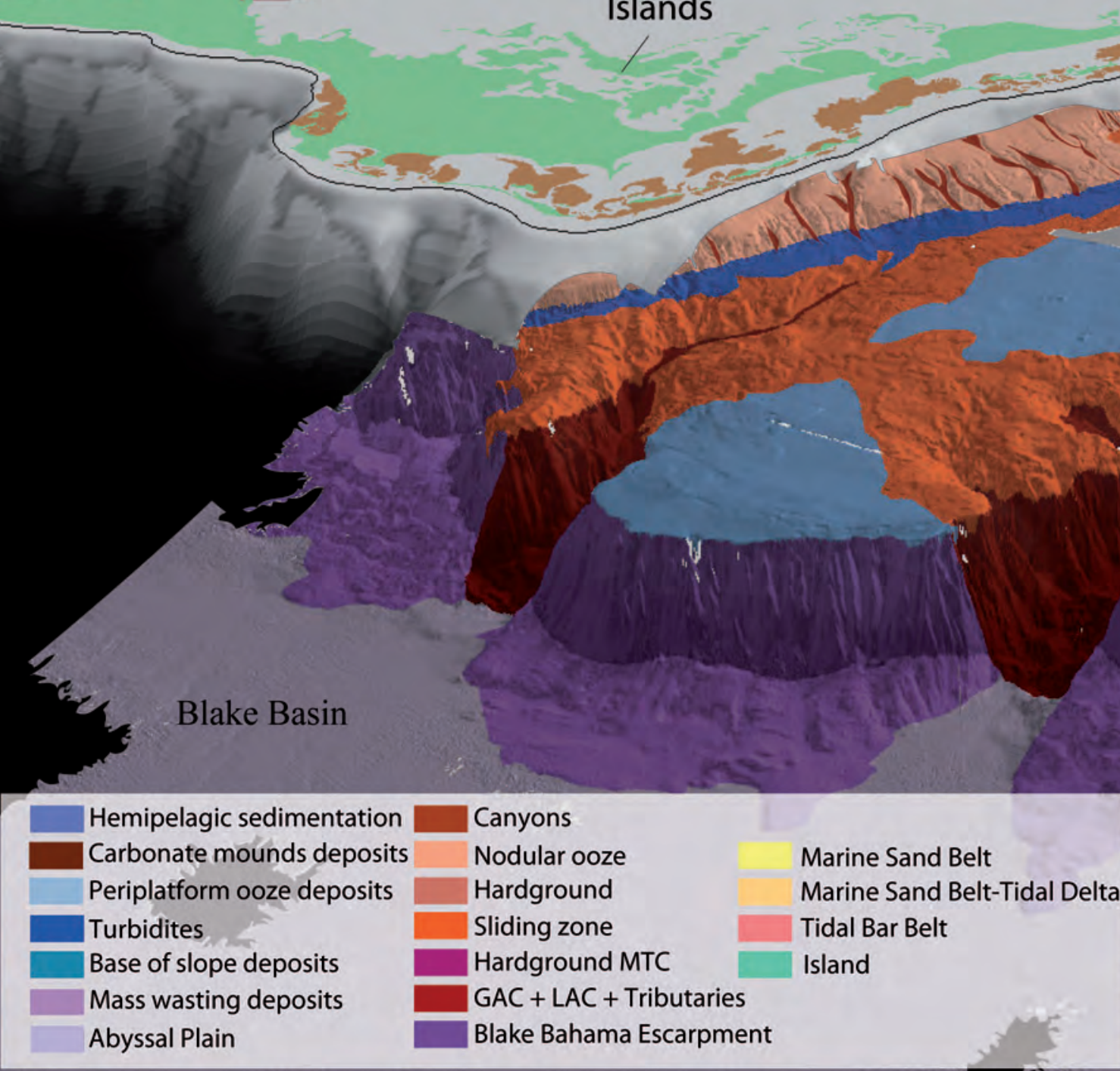

Blake Plateau

B
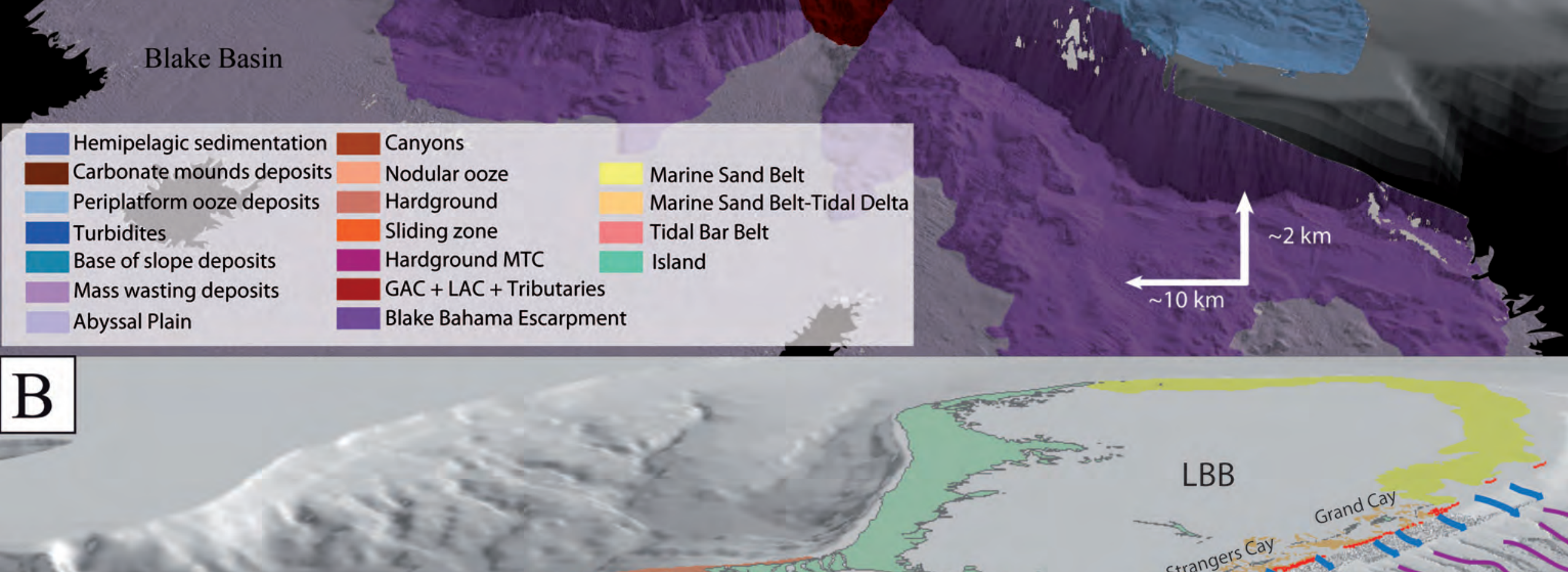

LBB

LBB drift

$y_{N}$

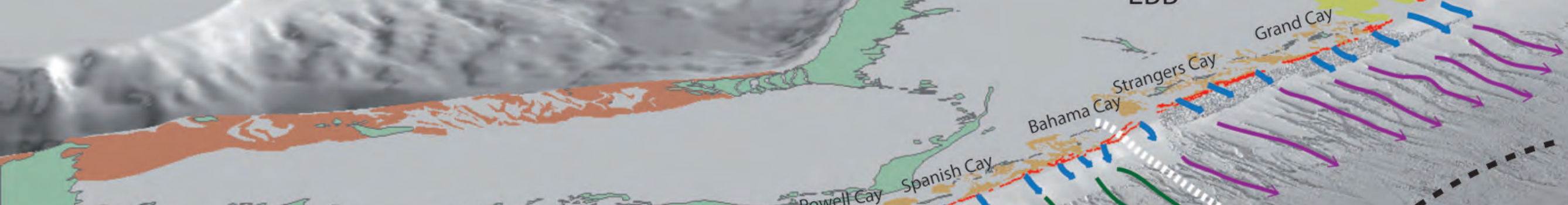

(3) Abaco $\begin{gathered}\text { Great } \\ \text { Island }\end{gathered}$ Great Guana Cay whale Cay
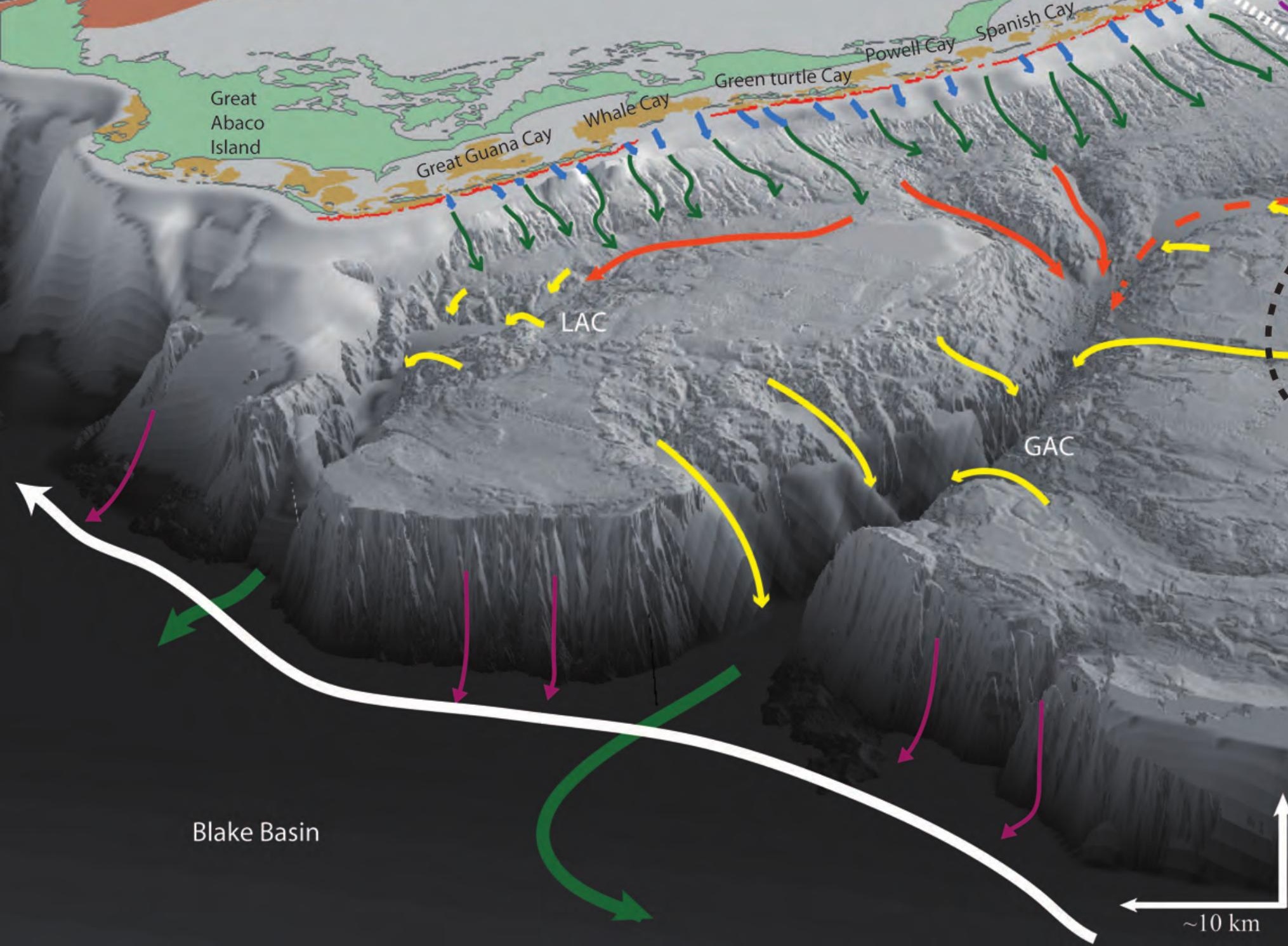

$\sim 2 \mathrm{~km}$

Off-bank

$\rightarrow$ Mass movements

$\rightarrow$ Low density currents

$\rightarrow$ High density currents

$\rightarrow$ Turbidity currents

Sliding motion

a) Antilles Current

$\rightarrow$ DWBC

Marine Sand Belt

Marine Sand Belt-Tidal Delta Tidal Bar Belt Island 
slide scars

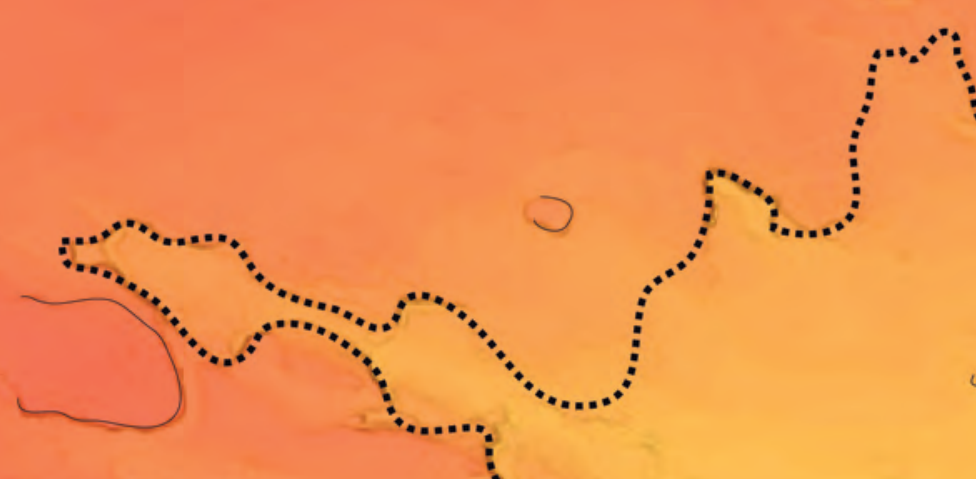

$-1300$

$-2300$

Amphitheatre-shaped

Bathymetry (m)

Bathymetry
-700

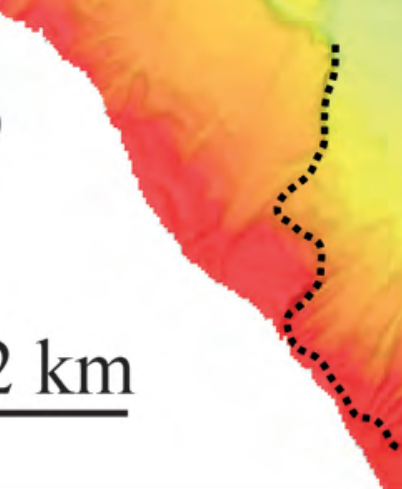
head 